\title{
Interactions by Disorder - A Matter of Context
}

\author{
Katrine Bugge ${ }^{1,2}$, Inna Brakti 1,2, Catarina B. Fernandes ${ }^{1,2}$, Jesper E. Dreier ${ }^{1,2}$, \\ Jeppe E. Lundsgaard ${ }^{1,2}$, Johan G. Olsen ${ }^{1,2}$, Karen Skriver ${ }^{1 *}$ and Birthe B. Kragelund ${ }^{1,2 *}$ \\ ${ }^{1}$ REPIN, Department of Biology, University of Copenhagen, Copenhagen, Denmark, ${ }^{2}$ Structural Biology and NMR \\ Laboratory, Department of Biology, University of Copenhagen, Copenhagen, Denmark
}

\section{OPEN ACCESS}

Edited by:

Wei Yang,

State College of Florida,

Manatee-Sarasota, United States

Reviewed by:

Vladimir N. Uversky,

University of South Florida,

United States

Jianhan Chen,

University of Massachusetts Amherst, United States

*Correspondence: Karen Skriver

KSkriver@bio.ku.dk

Birthe B. Kragelund bbk@bio.ku.dk

Specialty section:

This article was submitted to

Molecular Recognition,

a section of the journal

Frontiers in Molecular Biosciences

Received: 25 March 2020

Accepted: 11 May 2020

Published: 16 June 2020

Citation:

Bugge K, Brakti I, Fernandes CB, Dreier JE, Lundsgaard JE, Olsen JG, Skriver $K$ and Kragelund BB (2020) Interactions by Disorder - A Matter of Context. Front. Mol. Biosci. 7:110.

doi: 10.3389/fmolb.2020.00110
Living organisms depend on timely and organized interactions between proteins linked in interactomes of high complexity. The recent increased precision by which protein interactions can be studied, and the enclosure of intrinsic structural disorder, suggest that it is time to zoom out and embrace protein interactions beyond the most central points of physical encounter. The present paper discusses protein-protein interactions in the view of structural disorder with an emphasis on flanking regions and contexts of disorder-based interactions. Context constitutes an overarching concept being of physicochemical, biomolecular, and physiological nature, but it also includes the immediate molecular context of the interaction. For intrinsically disordered proteins, which often function by exploiting short linear motifs, context contributes in highly regulatory and decisive manners and constitute a yet largely unrecognized source of interaction potential in a multitude of biological processes. Through selected examples, this review emphasizes how multivalency, charges and charge clusters, hydrophobic patches, dynamics, energetic frustration, and ensemble redistribution of flanking regions or disordered contexts are emerging as important contributors to allosteric regulation, positive and negative cooperativity, feedback regulation and negative selection in binding. The review emphasizes that understanding context, and in particular the role the molecular disordered context and flanking regions take on in protein interactions, constitute an untapped well of energetic modulation potential, also of relevance to drug discovery and development.

Keywords: IDP, SLiM, protein interactions, context, flanking region, intrinsically disordered proteins, ensemble redistribution, interaction mechanism

\section{INTRODUCTION}

Living organisms depend on self-orchestrated interactions between molecules linked in interactomes of enormous complexity (Mosca et al., 2013; Cafarelli et al., 2017). In these, proteinprotein interactions must happen with a precision and in a timely manner that secure specificity and fidelity of the interactome. Protein interactions depend on electrostatics, hydrophobicity, dynamics and complementarity, as well as regulatory mechanisms enabling the complexes to trigger and assert the functions required, be it catalysis, signal transduction, transcription, mechanical structure or something else. There may even be a need for these aspects to function under different physicochemical and physiological circumstances. Importantly, proteins with intrinsically disordered properties, whether it is a completely intrinsically disordered protein (IDP) or a protein 
with an intrinsically disordered region (IDR), are key to network fidelity (Dosztányi et al., 2006; Oldfield et al., 2008; Staby et al., 2017; Uversky, 2018), and they exist in ensembles of almost isoenergetic states. Their complexity cannot be described by a single type of experiment but requires several complementary observations. Over the years, the range of amenable observations has broadened, the precision of the measurements improved, and the theoretical understanding of what an IDP is and how macromolecules interact is increasing rapidly (Kragelund and Skriver, 2020). It is therefore time to zoom out and embrace protein complex formation and function beyond the most central points of physical encounter and take the environment and context into account in a much broader term.

\section{Context Is Multidimensional}

The context of IDP interactions includes time and space, as well as the disordered chain in which the contact points are embedded. Traditionally, we have mostly considered context in relation to three-dimensional structures, but for IDPs this fails to provide us with insight into how context influences binding. Compared to structured proteins, IDP ensembles are more sensitive to changes in their settings, and by extension, the same is true for the interactions they engage in.

For many IDPs, their interactions - and hence their contacts to their partner molecule - are made via short, sequence-embedded motifs of limited information (Sharma et al., 2014; Davey et al., 2015). Short linear motifs (SLiMs) are more prevalent in IDPs, and the human proteome is estimated to contain $>100.000-$ possibly a million - SLiM instances (Davey et al., 2012; Tompa et al., 2014). SLiMs are typically 6-12 residues long and can usually be recognized by patterns of conserved residues within an otherwise sparsely conserved sequence stretch (Davey et al., 2012; Sharma et al., 2014; Krystkowiak and Davey, 2017), although sometimes, they are so degenerate as to go unnoticed by sequence analysis alone. The SLiM is the central anchoring site for many IDP interactions and a recent review discusses the molecular details of SLiM-based affinity and specificity (Ivarsson and Jemth, 2019).

In recent years, SLiMs have been studied extensively applying different methods, among them especially bioinformatics (Krystkowiak and Davey, 2017), but also by several different other structural and biochemical methods (Kragelund and Skriver, 2020). Through these studies, it has become clear that the properties of a complex (that is affinity, specificity, structure, kinetics, and thermodynamics) cannot always be explained solely by focusing on the SLiM interaction, but that the entire context of disorder and the presence of folded domains need to be considered (Figure 1A). For example, affinities have been modulated by changing the structural context outside of a SLiM via single residue mutations promoting secondary structure elements present in the bound state (Iešmantavičius et al., 2014) or by charge properties next to the SLiM (Stein and Aloy, 2008; Hertz et al., 2016; Palopoli et al., 2018; Prestel et al., 2019). Conformational heterogeneity, characteristic of many ID-based interactions (Fuxreiter, 2019), is also regulated by residues outside the SLiM-binding site, where they form transient heterogeneous contacts, which may facilitate partner-templated coupled folding and binding (Toto et al., 2016). No formal terminology exists for describing the context, and the immediate $\mathrm{N}$ - and C-terminal context of the SLiM will therefore here be referred to as the SLiM flanking regions. The boundary between what we define as SLiM and flanking regions is a continuum, likewise, so is the boundary between flanking regions and the remainder of the chain context. Limiting the flanking regions to, say, 20 residues on either side probably makes sense for most proteins, but some SLiMs may have shorter SLiM-like flanking regions of relevance (Figure 1B). In other cases, properties belonging to the chain may also contribute to binding affinity and specificity, and not necessarily through direct contact to the binding partner (Figure 1C). We will consider these as part of the context and not part of the flanking regions. Clearly, flanking regions are also part of the context and the boundary between flanks and the greater context is likely system dependent.

The present paper discusses disordered protein-protein interactions with a focus on context, and with a special emphasis on the disordered chain and how its properties affect protein interactions. Context has a broad meaning, being the physicochemical environment $(\mathrm{pH}$, viscosity, pressure, salt concentration, etc.), the biomolecular environment (interactors and location), or the physiological environment (cell-type, cell cycle, stress, etc.), but it is also the intramolecular context of the interaction; that is the peptide chain to which the interaction site belongs. Due to their abundance, SLiMs serve as important models/platform for the understanding of context in relation to disorder. However, interactions between IDPs may not necessarily be SLiM-based, but can also be mediated by disorder itself. This review highlights how flanking regions and the disordered contexts are emerging as important contributors to allosteric regulation, positive and negative cooperativity, feed-back regulation and negative selection in disorder-based binding and it poses important outstanding questions that need attention to enable a full comprehension of how disorder-based interactions operate.

\section{THE CONTEXT OF TIME AND SPACE}

Before we engage in discussing the chain properties of disorderbased interactions, it is important to recognize that IDPs function in different compartments of the cell, are distributed in different tissue types and can be both extracellular and intracellular. They operate in timed manners covering many different time scales including evolution, development, aging and temporal regulation needed for maintaining homeostasis and turnover during cell cycles. Such settings provide a spatiotemporal context capable of modulating IDP interactions.

\section{Isoforms Allow Context Adaptation}

The context of development may affect IDP interactions through, e.g., the specific expression of isoforms at different developmental stages that differ in their ability to interact with partners, as shown for the Ubx transcription factors (TFs), which are key players in Drosophila embryonic development (López et al., 1996; Hsiao et al., 2014). Similarly, many isoforms that differ in the length 

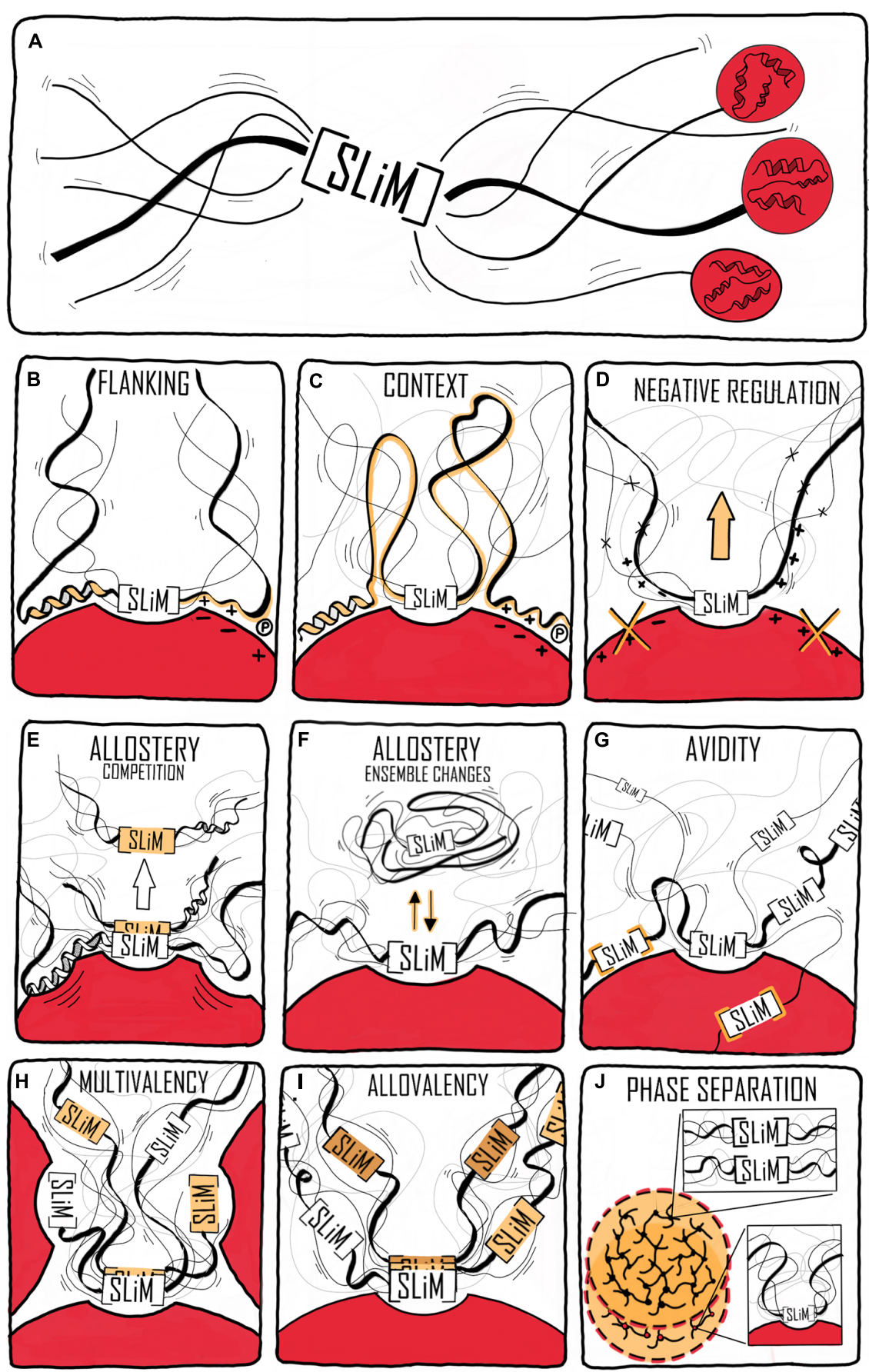

FIGURE 1 | Context contribution to disorder-based protein interactions. (A) A binding region within an IDP illustrated by a single SLiM. The binding region is embedded in a disordered chain in which additional features are present that can affect the interaction. The red spheres with helical structures illustrate that the IDR may be part of a modular protein and connected to folded domains. (B) Flanking regions can modulate IDP binding by, e.g., charge complementarity, secondary structure formation, and phosphorylation (illustrated by an encircled P). (C) Binding regions distant to the central binding site can contextually modulate binding. (D) Negative selection by means of mismatching flanking region properties. (E) Allosteric regulation through the flanking region via conformational changes in the folded partner (red) induced by IDP binding. This may also lead to partner selection as indicated by the second SLiM (in orange) leaving the binding site. (F) Allosteric regulation by ensemble redistribution of the disordered chain, here illustrated by changes in the degree of compaction. (G) Avidity by additional SLiMs or binding sites within the disordered chain binding outside the (or one of the) central contact point(s) (orange). (H) Multivalency by additional SLiMs or binding sites binding to different proteins resulting in dynamic binding illustrated by three chains with different colored SLiMs. (I) Contextual allovalency. Several SLiMs within the same disordered chain bind to the same binding site on the target protein - one at the time - and increase affinity through allovalency effects, here illustrated by three different chains of the ensemble, (J) Liquid-liquid phase separation (LLPS) by multiple SLiMs (top droplet and top zoom) or by SLiM:domain interactions (bottom droplet and bottom zoom). The red spheres represent a folded binding partner in all figures. 
and sequence context of their IDRs are distributed between different cell types and organelles, and experience different operating contexts. The sodium-proton exchanger (NHE) family is an example of this. NHEs are membrane proteins, and the nine isoforms have similar membrane transport functions, but have IDRs of different lengths with varying SLiM content and sequence (Nørholm et al., 2011; Hendus-Altenburger et al., 2014), suggesting that the mechanisms and regulations underlying their function in the membrane, differ. Some isoforms are brain specific, e.g., NHE6 and NHE9 (Schwede et al., 2014; Zhao et al., 2016), and some are ubiquitously located in the plasma membrane, such as NHE1, while other isoforms are localized in specific organellar membranes (Ohgaki et al., 2011; Prasad and Rao, 2015; Pedersen and Counillon, 2019). Thus, despite similar functions, the spatial context in which these proteins carry out their function is different, as a result of their different IDRs.

\section{Context Fluctuates With Time}

Time also affects the context in which IDPs work. At the long time scales, evolution changes the context and although sequences develop, emerging evidence suggests that orderdisorder patterns are evolutionary conserved whereas sequence is not, as exemplified by the plant NAM, ATAF, and CUC (NAC) TFs (Christensen et al., 2019). A comparison of five Ubx TF orthologs spanning 540 million years of evolution (Ronshaugen et al., 2002) revealed that the strength of the activation domains changed during evolution, and that the location of the activation domain moved relative to conserved motifs and sub-domain organization (Liu et al., 2018). Similarly, fine-tuning of the interaction of the IDR of the kinase Pbs2 to specifically bind one $\mathrm{SH} 3$ domain among a context of many others (Zarrinpar et al., 2003; Kelil et al., 2016) was obtained through evolution. At the shorter timescale of the human life span, mutations accumulate, and while most are benign, stochastic changes can generate dysfunctional proteins, ultimately leading to disease. A proteome-wide study found that $22 \%$ of all human disease mutations locate to disordered regions (Uyar et al., 2014). Some disease-related mutations are SLiM-conserving, leaving affinity unperturbed, but with mutations located in the context resulting in altered specificity, cross-reactivity, and self-association as in the case of some neurodegenerative diseases (Uyar et al., 2014; Xiang et al., 2015). Finally, on one of the shorter time scales represented by the biological clock - the circadian rhythm which is physiological processes happening on a 24-h cycle (BellPedersen et al., 2005), the external context of IDPs differs due to changes in the available interactome. In mammals, the cycle is largely controlled by a heterodimer constituted of circadian locomotor output cycles kaput (CLOCK) and the TF brain and muscle arnt-like protein-1 (BMAL1) (Rey et al., 2011; Huang et al., 2012) and here, BMAL1 operates in different contexts depending on the time of day. CLOCK:BMAL1 regulates the transcription of thousands of different genes and the main regulators of CLOCK:BMAL1 activity are the proteins period 1 and 2 (Per 1 and Per2) and cryptochrome 1 and 2 (Cry1 and Cry2), the genes of which are themselves regulated by CLOCK:BMAL1 (Gekakis et al., 1998). Per and Cry dimerize, interact with CLOCK:BMAL1 and inhibit transcriptional activity
(Partch et al., 2014) in a negative feedback loop (Gekakis et al., 1998). Intriguingly, the activation domain of BMAL1 is further regulated by a proline switch, in which the Pro isomerizes between cis- and trans-conformations. Even though the Pro is the penultimate C-terminal residue, it still has a significant impact on the timekeeping ability of BMAL1. When the switch is locked in trans, the circadian rhythm is shortened to an extent comparable to deleting the switch, and when cyclophilins, a family of cis-trans peptidyl-prolyl isomerases are inhibited, the rhythm is prolonged (Figure 2) (Gustafson et al., 2017). This is suggesting that either the dynamics of the conformations is important or that the cis conformation is necessary for BMAL1 function. The fluctuation in CLOCK:BMAL1 activity that happens on a 24 -h basis is dependent on changes in access to interaction partners, and in this way the context impacts the activity of the cell, contributing to the difference in organismal behavior during night and day.

In conclusion, the spatiotemporal context affects how disorder-based interactions operate, and with this in mind, we will continue with a more direct focus on the physicochemical context of the IDP itself.

\section{THE FLANKING REGIONS AS CONTEXT}

As defined above, flanking regions are here considered to be the \pm 20 residues $\mathrm{N}$ - and C-terminal to a SLiM or main contact site (Figure 1B), and may or may not contribute to binding affinity, specificity, and regulation of an interaction. Although rarely comprising 20 residues, the flanking regions may have strong modulatory impact on interactions, and they have been suggested to possess specific amino acid compositions (Fuxreiter et al., 2007). In this section, several examples of affinity

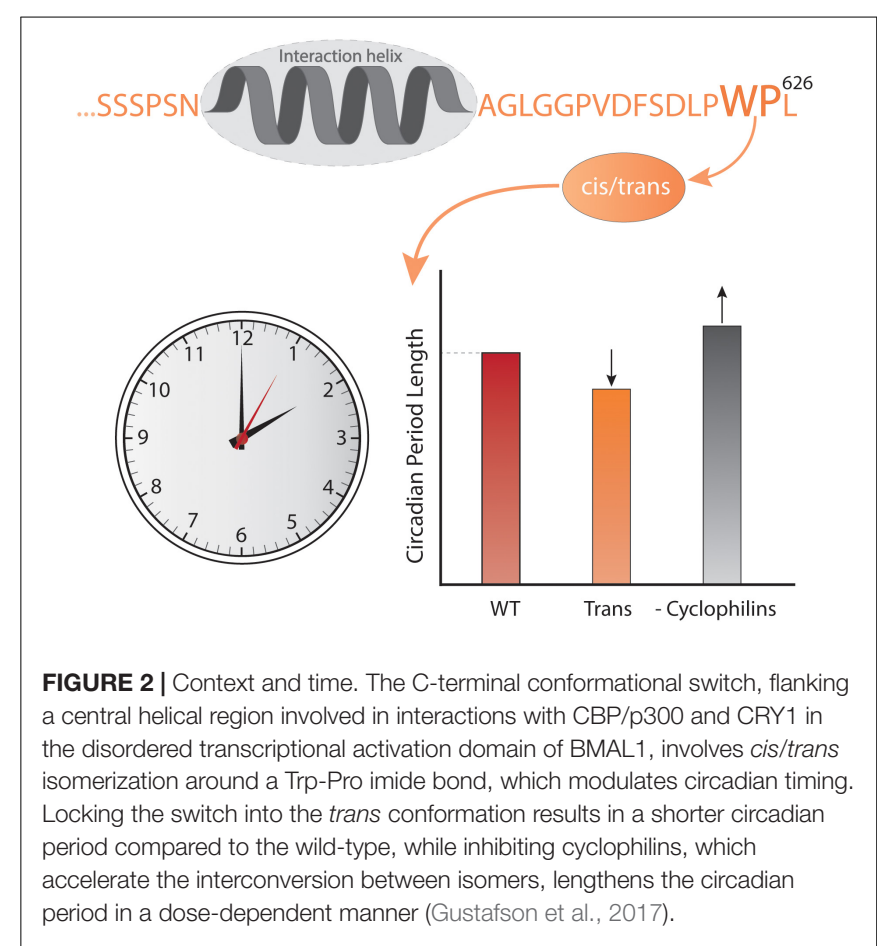


modulation by flanking regions will be highlighted, as well as examples where the flanking regions play regulatory roles.

\section{Flanking Regions in Targeting}

Many essential SLiMs have been identified in proteins destined for membranes. Acidic di-Leu- and Tyr-based internalization motifs are prominent examples of trafficking signals, which are involved in recruitment of clathrin-coated vesicles to membranes (Heilker et al., 1999). Their functional potency is illustrated by substitutions in their IDRs causing the syndrome glucose transporter causative of GLUT1 deficiency by creating di-Leu motifs (Meyer et al., 2018). Structural analysis of the AP2 clathrin adaptor complex with a bound di-Leu peptide revealed the functional importance of the residues of the core motif [DE] xxxL[LI] (Table 1) (Kelly et al., 2008). However, based on structural analysis, the ensemble context of the core motif, including the two residues C-terminal and a phosphorylated Ser five residues $\mathrm{N}$-terminal of the first leucine were also suggested to affect binding (Kelly et al., 2008) (Table 1). Similarly, biochemical and structural analysis of the interactions between the di-Leu motif of the cation-dependent mannose 6-phosphate receptor and GGA proteins, implicated in protein trafficking between the Golgi apparatus and endosomes, revealed that both the $\mathrm{N}$-and C-terminal di-Leu motif flanking regions influenced binding affinities. Thus, binding to the GGA proteins requires a precise spacing between the di-Leu and the free C-terminus (Misra et al., 2002) (Table 1).

Retrieval of many endoplasmic reticulum (ER)-resident proteins from post-ER compartments depends on a C-terminal [HKR]DEL motif (Majoul et al., 2001). Recent determination of

TABLE 1 | Selected examples of SLiMs affected by flanks and contexts to regulate function.

\begin{tabular}{|c|c|c|c|c|c|}
\hline Core motif* & Parent protein & $\begin{array}{l}\text { Extension of core motif } \\
\text { by flanks and context }\end{array}$ & Function of motif & $\begin{array}{l}\text { Function of flanks and } \\
\text { context }\end{array}$ & References \\
\hline$P x x P$ & Pbs2 & Various flanks & Binding of $\mathrm{SH} 3$ domains & $\begin{array}{l}\text { Negative selection to } \\
\text { increase specificity }\end{array}$ & $\begin{array}{l}\text { Zarrinpar et al., 2003; } \\
\text { Kelil et al., } 2016\end{array}$ \\
\hline IXxLL & BMAL1 & $\begin{array}{l}\text { Very C-terminal residues, } \\
20 \text { positions from IxxLL }\end{array}$ & $\begin{array}{l}\text { Binding of Cry and CBP to } \\
\text { regulate the circadian } \\
\text { rhythm }\end{array}$ & $\begin{array}{l}\text { Allosteric regulation to } \\
\text { regulate transcription in } \\
\text { negative feed-back loop }\end{array}$ & $\begin{array}{l}\text { Heery et al., 1997; } \\
\text { Garg et al., } 2019\end{array}$ \\
\hline [DE]xxxL[LI] & CD4 & $p S[D E] x x x L[L I] x x$ & $\begin{array}{l}\text { Trafficking motif which } \\
\text { binds clathrin adaptor } \\
\text { proteins }\end{array}$ & Modulation of affinity & Kelly et al., 2008 \\
\hline [DE]XxLL & $\begin{array}{l}\text { Mannose 6-phosphate } \\
\text { receptor }\end{array}$ & $x x[D E] x x L L x x-C O O H$ & $\begin{array}{l}\text { Trafficking between Golgi } \\
\text { and endosomes }\end{array}$ & Modulation of affinity & $\begin{array}{l}\text { Doray et al., 2002; } \\
\text { Misra et al., } 2002\end{array}$ \\
\hline [KR]DEL-COOH & $\begin{array}{l}\text { Various ER-localized } \\
\text { proteins }\end{array}$ & $\begin{array}{l}x \times[\mathrm{KR}] \mathrm{DEL}-\mathrm{COOH} / \\
\Omega \times \Omega \mathrm{KDEL} \\
\mathrm{KDEL}-\mathrm{COOH}\end{array}$ & $\begin{array}{l}\text { Recognition by KDEL } \\
\text { receptors for ER retention }\end{array}$ & Modulation of specificity & $\begin{array}{l}\text { Alanen et al., 2011; Mei } \\
\text { et al., } 2017\end{array}$ \\
\hline SxIP & CLIP-170 & $\begin{array}{l}(\mathrm{Sx}[\mathrm{IL}] \mathrm{P})_{n} \mathrm{CAP}-\mathrm{G} \\
\mathrm{Sx}[\mathrm{IL}] \mathrm{PCAP}-\mathrm{G}\end{array}$ & Targeting to microtubules & $\begin{array}{l}\text { Multivalency to modulate } \\
\text { affinity }\end{array}$ & Chen et al., 2019 \\
\hline $\begin{array}{l}\mathrm{Qxx} \Phi \times x[\mathrm{FHT}][\mathrm{FHY}] \\
\mathrm{Qxx} \Phi \times x[\mathrm{FHT}][\mathrm{FHY}]-\mathrm{x}_{4}-[\mathrm{KR}] \\
\Phi[\mathrm{KR}] \Omega \Phi \Phi[\mathrm{KR}]\end{array}$ & $\begin{array}{l}\text { PCNA partners (e.g., } \\
\text { polymerases, E3-ligases, } \\
\text { nucleases, helicases) }\end{array}$ & Charges $(R / K)$ on each side & $\begin{array}{l}\text { Replication fork localization } \\
\text { motif to PCNA }\end{array}$ & $\begin{array}{l}\text { Modulation of affinity by up } \\
\text { to } 4 \text { orders of magnitude }\end{array}$ & $\begin{array}{l}\text { Moldovan et al., 2007; } \\
\text { Gilljam et al., 2009; } \\
\text { Prestel et al., } 2019\end{array}$ \\
\hline$[\mathrm{IL}] \times \mathrm{C} \times[\mathrm{DE}]$ & $\begin{array}{l}\text { Host and viral interactors of } \\
\text { Rb proteins }\end{array}$ & Negative charges & Binding to Rb family & Modulation of affinity & Palopoli et al., 2018 \\
\hline LxxIxE & Protein phosphatase $2 \mathrm{~A}$ & Negative charges & PP2A binding motif & Affinity modulators & Hertz et al., 2016 \\
\hline EFFDAxE & OSBP & {$[E D]_{6} E F F D A x E$} & $\begin{array}{l}\text { Bridging between ER and } \\
\text { other compartments }\end{array}$ & $\begin{array}{l}\text { Initial low-affinity } \\
\text { electrostatic binding }\end{array}$ & $\begin{array}{l}\text { Loewen et al., 2003; } \\
\text { Furuita et al., } 2010\end{array}$ \\
\hline TQT & ASCIZ & Additional TQT & $\begin{array}{l}\text { Binding of LC8 to regulate } \\
\text { its level }\end{array}$ & $\begin{array}{l}\text { Multivalency mediating } \\
\text { positive and negative } \\
\text { cooperativity }\end{array}$ & Clark et al., 2018 \\
\hline TPKK & $\mathrm{p} 27^{\text {Kip } 1}$ & Charge distribution & $\begin{array}{l}\text { Phosphorylation motif. } \\
\text { Leads to degradation }\end{array}$ & $\begin{array}{l}\text { Regulation of } \\
\text { phophorylation }\end{array}$ & Das et al., 2016 \\
\hline $\mathrm{GG} \times \mathrm{G} \times \mathrm{D} \times[\Omega, \Psi]$ & Adenylate cyclase toxin & C-terminal disorder & $\mathrm{Ca}^{2+}$ binding and folding & Overall folding & $\begin{array}{l}\text { Sotomayor Pérez et al., } \\
2010\end{array}$ \\
\hline $\mathrm{LP}[\mathrm{Q} / \mathrm{E}] \mathrm{L}$ & CITED2 & $\alpha$-helix-LP[Q/E]L & $\begin{array}{l}\text { Binding to the TAZ1 } \\
\text { domain of CBP }\end{array}$ & Anchoring and competition & Berlow et al., 2017 \\
\hline$[\mathrm{DE}] \mathrm{X}[1,2][\mathrm{YF}] \mathrm{X}[1,4][\mathrm{DE}] \mathrm{L}$ & DREB2A and ANAC013 & Conserved ID patterns & $\begin{array}{l}\text { Binding to cellular hub } \\
\text { RCD1 }\end{array}$ & $\begin{array}{l}\text { Negative and positive } \\
\text { allostery }\end{array}$ & $\begin{array}{l}\text { O'Shea et al., 2017; } \\
\text { Christensen et al., } 2019\end{array}$ \\
\hline $\mathrm{RX} \mathrm{n}_{n 1} \mathrm{R} ; n_{1} \leq 2$ & Rpl5 & $\begin{array}{l}\mathrm{RX}_{n 1} \mathrm{R} \mathrm{x}_{m} \mathrm{R} \mathrm{X}_{n 1} \mathrm{R} ; n_{1} \leq 2 \\
m \geq 2\end{array}$ & Phase separation & $\begin{array}{l}\text { Multivalency to modulate } \\
\text { affinity }\end{array}$ & $\begin{array}{l}\text { Mitrea et al., 2014, } \\
2016\end{array}$ \\
\hline$\Phi \Phi W \Phi \Phi\llcorner F$ & GCN4 & $\begin{array}{l}\text { Additional hydrophobic } \\
\text { patches }\end{array}$ & $\begin{array}{l}\text { Transcriptional activation } \\
\text { and phase separation }\end{array}$ & $\begin{array}{l}\text { Multivalency needed for } \\
\text { avidity in function }\end{array}$ & $\begin{array}{l}\text { Warfield et al., } 2014 ; \\
\text { Boija et al., } 2018\end{array}$ \\
\hline
\end{tabular}

*The order of the motifs in this table follows the order according to which they are mentioned in the main text. 
the structure of the complex between the KDEL receptor and a KDEL peptide revealed how the SLiM residues contribute to binding (Bräuer et al., 2019). However, previous analysis of the [HKR]DEL flanks in human ER-localized proteins indicated that two residues $\mathrm{N}$-terminal (positions -5 and -6 ) of the [HKR]DEL motif also played important roles for KDEL receptor recognition, and that different receptors have different preferences with respect to these positions (Alanen et al., 2011) (Table 1). Furthermore, simulation-guided studies revealed that aromatic residues in the extended motif $\Omega x \Omega K D E L$ also contributed to the interactions (Mei et al., 2017) (Table 1). Thus, here flanking regions may or may not be part of an extended motif, but constitute an important gearing of binding affinity as well as specificity (Figure 1B).

The microtubule network represents an essentially membrane-less compartment and is regulated by microtubule plus-end-tracking proteins (+TIPs) (Akhmanova and Yap, 2008; Jiang et al., 2012). Targeting of +TIPs to microtubules is mediated by SxIP anchoring motifs, found in, e.g., cytoplasmic linker protein 170 (CLIP-170), which engages in multivalent interactions with the protein End Binding 1 (EB1) (Chen et al., 2019). Whereas a central SxIP motif in CLIP-170 binds EB1 weakly, the so-called cytoskeleton-associated protein (CAP)-Gly domains are present in the flanking region and increase binding affinities by targeting different EB1 regions than the SxIP motif. Furthermore, additional N-terminal SxIP and SxIP-like motifs further increase binding affinities. In this binding model, the context of the central CLIP-170 SxIP motif provides avidity to the CLIP-170-EB1 interaction (Table $\mathbf{1}$ and Figures 1B,G) (Chen et al., 2019).

\section{Flanking Regions for Affinity Gearing}

Proliferating cell nuclear antigen (PCNA) is an example where binding partners use a SLiM for anchoring (Moldovan et al., 2007). PCNA has an enormous interactome (Moldovan et al., 2007; Prestel et al., 2019) and common to its binding partners is the Qxx $\Phi \times x[F H T][F H Y]$ PIP-box motif of which variations are known, including the PIP-degron for degradation QTDФxx[FHT][FHY]-X 4 -[KR] (Havens and Walter, 2009) (Table 1), and the APIM motif $[\mathrm{KR}] \Omega \Phi_{2}[\mathrm{KR}]$ for cytosolic partners (Gilljam et al., 2009; Sebesta et al., 2017). The motifs bind weakly in the low micromolar range, and the only currently known partner with nM affinity is p21 (Zheleva et al., 2000). Still, motifs harboring the canonical motif can have different affinities for PCNA, and the motif can degenerate, even to a degree where the similarity to the PIP-box is lost (Gilljam et al., 2009), but with retainment of similar affinities (Prestel et al., 2019). Recent work shed light on this paradox by showing that the flanking regions immediately surrounding the PIP-box had strong affinity-modulating activity through electrostatics. By increasing the number of positive charges in the flanking regions, the affinity for PCNA was modulated by up to four orders of magnitude (Figure 3 and Table 1) (Prestel et al., 2019). A similar effect was seen for pocket proteins of the retinoblastoma protein $(\mathrm{Rb})$ family, that bind the SLiM LxCxE, present in host and viral interactors of the Rb family (Jones et al., 1990; Noval et al., 2013). Here, negative charges in the flanking regions act as affinity and specificity modulators (Figure 1B) (Palopoli et al., 2018), conversely regulated by introduction of negative charge from phosphorylation of binding regions on the Rbs (Knudsen and Wang, 1996). Similar charge modulation by flanks has been seen for the regulatory domain of protein phosphatase 2A (PP2A), where negative charges C-terminal to the SLiM (LxxIxE) enhanced affinity via electrostatics with a basic patch on PP2A; also mouldable by phosphorylation (Hertz et al., 2016) (Table 1), and for SH3 binding regions, where positive charges in the flanking regions modulate affinity (Figure $\mathbf{1 B}$ and Table 1) (Gorelik and Davidson, 2012; Teyra et al., 2012). In these cases, the context provides additional negative selection via mismatching flanking regions (Figure 1D and Table 1). How electrostatics contribute to binding, e.g., via salt bridge formation or mean-field type interactions (see below), is not clear.

\section{Flanking Regions as Motif Modulators}

Communication between cell compartments also depend on context. Proteins with FFAT motifs (Loewen et al., 2003) communicate between the ER and other compartments by bridging (Murphy and Levine, 2016; Costello et al., 2017; Slee and Levine, 2019). The core of the FFAT motif, EFFDAxE, found in, e.g., oxysterol-binding protein (OSBP) (Furuita et al., 2010), is an extended region of seven residues (Table 1), the second and fifth of which bind into pockets in the integral ER membrane

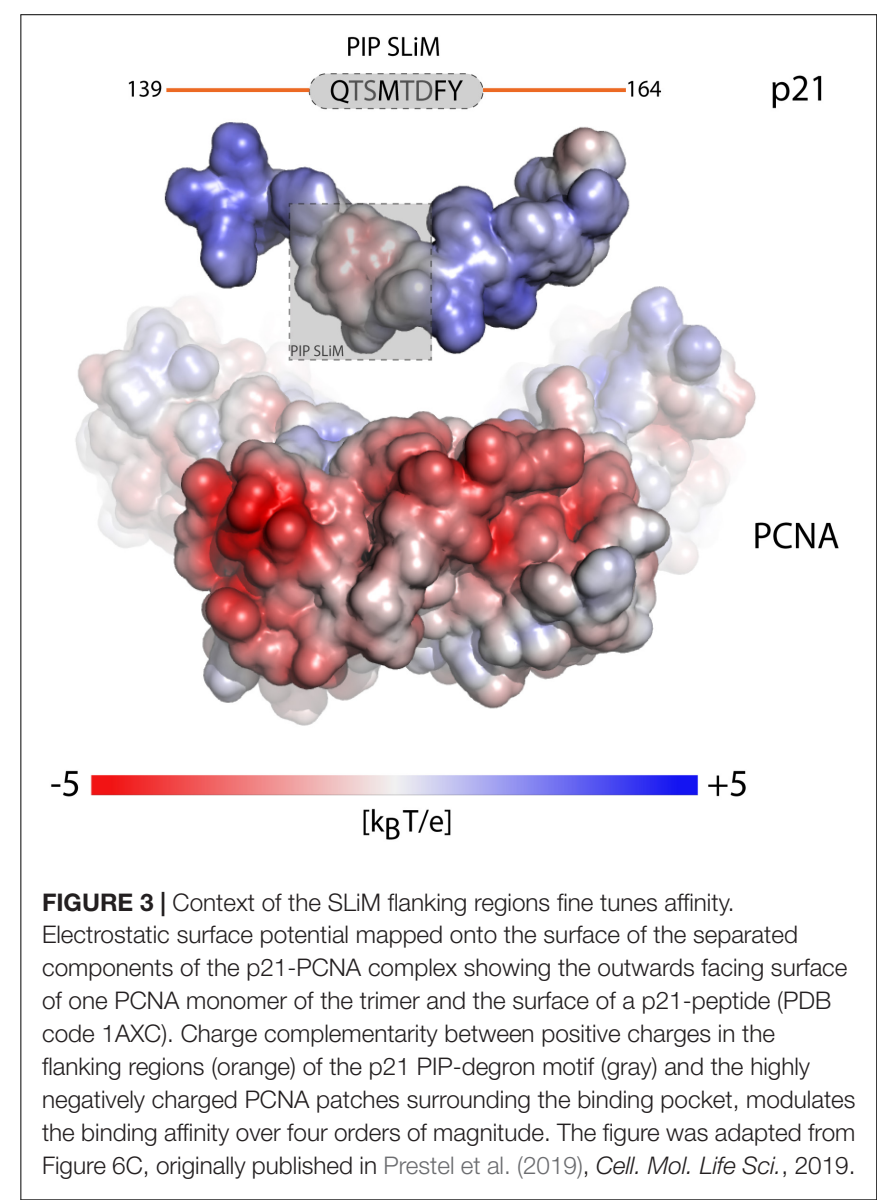


protein VAMP-associated protein (VAP) (Kaiser et al., 2005). Prior to binding of the core motif, an acidic tract positioned $\mathrm{N}$-terminally to the motif mediates low-affinity electrostatic interactions with VAP (Figure 1B) (Furuita et al., 2010). Thus, here the context may lead to acceleration of the interaction via encounter complex formation.

The flanking regions may furthermore contribute mechanistically to disorder-based interactions. Cooperativity driven by flanking regions is elegantly demonstrated by the IDRs constituting the activation domain of the zinc finger TF ataxia telangiectasia mutated substrate Chk2-interacting $\mathrm{Zn}^{2+}$-finger protein (ASCIZ) (Clark et al., 2018). ASCIZ uses 11 out of 17 highly conserved TQT SLiMs to bind the dimeric hub protein LC8 (Ranaldi et al., 1994; Rapali et al., 2011), whereas Chia, another LC8 binding IDP uses three out of four TQT SLiMs to bind, whose affinities depend on the flanking regions in a non-predictable manner (Clark et al., 2016). The multivalency of ASCIZ and Chia allows both positive and negative cooperativity in its interaction with LC8. ASCIZ binding to LC8 generates a scaffold (Clark et al., 2015) onto which additional LC8s bind with increased affinity (Figure $\mathbf{1 H}$ and Table $\mathbf{1}$ ). Then, negative cooperativity regulates the formation of higher-order LC8 assemblies to ensure that low-occupancy complexes dominate at saturating concentrations of LC8 to prevent switching off transcription completely (Clark et al., 2018). Thus, for the disordered ASCIZ and Chia, both flanks and context affect binding affinity and in vivo regulation of activity.

Finally, when SLiMs are placed in pre-structured contexts, defined as molecular recognition features (MoRFs) (Malhis and Gsponer, 2015; Sharma et al., 2018) or pre-structured motifs (PreSMos) (Lee et al., 2012), the flanking regions can modulate the structural context of the motif and hence interactions. This has been exemplified by prolines in flanking regions impacting helicity, and it has by computation, e.g., been shown that when a proline was mutated in an $\mathrm{N}$-terminal flanking region, helicity was significantly decreased, whereas when mutated in the C-terminal flanking region, the helical content increased (Lee et al., 2014). Proline structural modulation was later shown to impact target binding, with the P27A-variant of p53 binding more tightly to $\mathrm{Mdm} 2$ when helicity was boosted (Borcherds et al., 2014).

The examples given above are part of an emerging picture of the importance of the flanking context for SLiM-driven IDP interactions. They have in common that the aromatic and charged residues of the core SLiM motif are flanked by additional charged or aromatic residues that initiate and enhance binding as well as provide a platform for negative selections and cooperativity (Figures 1B,D,H). In this way, flanking regions - or interaction sites along the chain - may constitute an affinity gearing of the core SLiM.

\section{THE CONTEXT OF THE DISORDERED CHAIN}

Most SLiMs are embedded in disordered chains of various lengths, some as long as 500 residues (Christensen et al., 2019) and some as short as 30. Furthermore, some SLiMs and their disordered chain are connected to globular domains of different sizes and function, while others exist in a fully disordered setting. The properties of the chain (ordered, disordered, long, short, sequence-, and ensemble properties) are part of the context and may influence interactions. In the following we will highlight examples that illustrate how chain properties may modulate disorder-based interactions.

\section{The Context of Sequence Properties of the Chain \\ Influence of Amino Acid Composition on Chain Properties}

Sequence properties are an important factor for compaction of disordered chains (Das et al., 2015; Martin et al., 2016, 2020). To date, various studies have assessed the sequenceencoded conformational preferences of IDPs, using concepts from polymer physics reviewed in Mao et al. (2013) and by combining several biophysical techniques with molecular simulations. These altogether point toward compositional parameters such as the net charge (Marsh and Formankay, 2010; Muller-Spath et al., 2010) or more specifically the distribution of charges (Das and Pappu, 2013), and proline residues (Marsh and Forman-kay, 2010; Martin et al., 2016) as being key determinants for their chain dimensions. Alterations to the net charge of IDPs, through for example alternative splicing or posttranslational modifications, can greatly affect their compaction and hence functions. A notable example was reported for the cyclin-dependent kinase inhibitor p27 Kip 1 . Here, modifications of the conserved distribution of charged residues in the flanking region of the SLiM TPKK provided a mechanism for controlling the phosphorylation efficiency of the SLiM Thr, leading to degradation of $\mathrm{p} 27^{\text {Kip } 1}$, and thus being responsible for entry into the S-phase of the cell cycle (Das et al., 2016) (Table 1). As most IDPs are polyampholytes (Das et al., 2015), modifications to SLiM flanking regions modulating their charge state (by e.g., phosphorylation) may induce transitions in the conformational ensemble of the disordered chain enabling allosteric regulation of motif accessibility (Figure 1F). Interestingly, while hydrophobicity has been suggested to play a marginal role in IDR compaction (Marsh and Forman-kay, 2010), a correlation between the fraction and patterning of aromatic residues and chain compaction was recently established (Sørensen and Kjaergaard, 2019; Martin et al., 2020). IDPs can be highly phosphorylated (Iakoucheva et al., 2004), which further introduces an increased $\mathrm{pH}$ sensitivity of disorder-based interactions, as phosphate groups titrate in the physiological $\mathrm{pH}$ range $(\mathrm{pKa}$ pTyr $=5.83, \mathrm{pSer}=6.01, \mathrm{pThr}=6.30)$ (Hendus-Altenburger et al., 2019). Differential effects of IDPphosphorylation have been observed, which may increase or decrease transient helicity in the vicinity of binding motifs, which in turn contributes to selection and deselection of binding partners as well as initiating degradation (Bah and FormanKay, 2016; Mylona et al., 2016; Hendus-Altenburger et al., 2017). Phosphorylation may also lead to global folding, as observed for the disordered eukaryotic translation initiation factor $4 \mathrm{E}$ binding 
protein 2 (4EBP2), which binds eukaryotic translation initiation factor 4E (eIF4E) and suppresses cap-dependent translation initiation. 4EBP2 folds upon phosphorylation of specific sites, and the more folded 4EBP2 becomes, the lower its affinity for eIF4E (Bah et al., 2015).

\section{Influence of Amino Acid Composition and the Physicochemical Environment on Compaction}

Due to their higher degree of solvent-contact, IDPs are expected to be more sensitive to changes in the environment and consequently, so will their interactions. Temperature, $\mathrm{pH}$, ions, solvent, salt concentration, and viscosity influence chain compaction as well as IDP interactions. For example, $\mathrm{pH}$ is highly connected to cellular location, as, e.g., intracellular $\mathrm{pHs}$ range from $\mathrm{pH} 4.7$ in the lysosomes to $\mathrm{pH} 8.0$ in the mitochondria. Thus, depending on location (Casey et al., 2010), IDPs may compact, gain secondary structure, or engage in folding or partial folding when the $\mathrm{pH}$ changes. Prothymosin- $\alpha$ (ProT $\alpha$ ), a highly acidic, nuclear IDP, is expanded at neutral $\mathrm{pH}$, but compacts as the $\mathrm{pH}$ decreases (Uversky et al., 1999). Similarly, proteins with high overall positive charge, such as core histones, partially fold when $\mathrm{pH}$ increases, affecting DNA binding (Hansen et al., 1998; Munishkina et al., 2004). Another example is the highly positively charged myelin basic protein (MBP), essential for the formation and stability of the myelin sheath in the central nervous system (Majava et al., 2008; De Avila et al., 2014). MBP is disordered, but folds into an $\alpha$-helical structure upon electrostatic interaction with the membrane (Polverini et al., 1999; Harauz et al., 2009), a transition highly regulated by salt and $\mathrm{Ca}^{2+}$ (Raasakka et al., 2019). A similar behavior was also observed for the IDP $\alpha$-synuclein (aSN) (Georgieva et al., 2008; Fusco et al., 2014; Cholak et al., 2020).

Chain compaction may further be affected by metal ions, as observed for $\mathrm{Zn}^{2+}$ binding to ProT $\alpha$, and to histatin, a small peptide of the mouth, here promoting formation of higher order structures (Cragnell et al., 2019). For both IDPs, these are $\mathrm{Zn}^{2+}$-specific effects (Yi et al., 2007; Cragnell et al., 2019). Similarly, $\mathrm{Ca}^{2+}$-binding to the C-terminal of aSN is specific, with other divalent cations showing much lower affinity (Lowe et al., 2004). For the disordered region of the adenylate cyclase toxin (Chenal et al., 2009), $\mathrm{Ca}^{2+}$ binding to $>40$ repeats in toxin motifs (RTX) GGxGxDx[ $\Omega, \Psi]$ led to folding into a $\beta$-roll structure (Sotomayor Pérez et al., 2010) central to its secretion (O'Brien et al., 2018) (Table 1). In this case, binding to the RTX motifs was not enough to induce folding, but required the presence of a C-terminal disordered flanking region (Sotomayor Pérez et al., 2010). However, ions not only affect structure and conformational properties via distinct binding, but their presence can also lead to changes in the ensemble, as shown for five different IDPs, which all expanded due to an increase in salt concentration (Vancraenenbroeck et al., 2019). Salts also tune disorder-based affinities and binding kinetics, as demonstrated for two different IDPs (Wicky et al., 2017), where the observed effects were dependent on the specific ions and not simply correlated to the ionic strength.

Thus, the conformational space sampled by the disordered chain is intimately linked to its physicochemical properties and to those of the surrounding environment. This ensemble can be shifted by alterations to the chain properties by extrinsic factors such as temperature, ions and salt concentration or by intrinsic factors such as post translational modifications or changes in protonation state.

\section{The Context of Chain Dynamics Fast Chain Dynamics in Specialized Interaction Mechanisms}

Recently, it has become clear that high degrees of fast, long-range dynamics may be retained in IDP complexes, and for some of the more recently discovered IDP interaction mechanisms, the context of the chain dynamics is an important prerequisite for interaction. This is the case for the interaction of the intrinsically disordered Phe-Gly-rich nucleoporins (FG-Nups) and nuclear transport receptors (NTRs). FG-Nups fill the central cavity of the nuclear pore complex, allowing passage of large molecules only when bound to NTRs. The interaction of FG-Nups with NTRs occur through the FG-SLiMs, which individually have NTR-affinities in the millimolar range (Milles et al., 2015). However, by combining many FG-SLiMs, an affinity in the nM-range is achieved (Hough et al., 2015). This avidity effect (Figure 1G) is facilitated by the retained flexibility and plasticity in the bound state of the FG-Nups, resulting in fast binding and unbinding of the individual motifs to different sites. The resulting highly dynamic multivalent interaction type enables high specificity along with a fast transport rate though the pore (Milles et al., 2015). Another example is the pM-affinity electrostatically driven interaction between $\mathrm{H} 1$ and its chaperone ProT $\alpha$ (Borgia et al., 2018). Here the retainment of flexibility of the two IDPs as well as their long-range dynamics in the complex allow rapid interconversion between many different conformations on the 100-ns time scale, facilitating a mean-field type electrostatic interaction between all charges (Borgia et al., 2018). Finally, pre-existence of chain disorder may allow for special cases of allovalency, as shown for the IDP Sic1 binding to cell-division control protein 4 (Cdc4). Here, multivalency from several identical sites distributed along a disordered chain binding to the same binding site increased binding affinity via allovalency (Figure 1I). The binding is cooperative, with almost no detectable binding until a sixth arbitrary site among ten becomes phosphorylated, producing strong binding (Mittag et al., 2008); a scenario only possible in the context of a flexible, dynamic chain (Locasale, 2008).

\section{Chain Dynamics in Partner Selection}

The context of chain dynamics also partakes in the recognition and competitive interactions of disordered TFs and hub proteins, as exemplified by the interaction of the TFs hypoxia-inducible factor (HIF)- $1 \alpha$ and CBP/P300 interacting trans-activator with ED-rich tail domain 2 (CITED2) with the telomere length regulator 1 (TAZ1) domain of the general transcriptional coregulatory CBP (Figure 1E) (Berlow et al., 2017). The two TFs use the core motif $\mathrm{LP}[\mathrm{Q} / \mathrm{E}] \mathrm{L}$ for binding to the same site on TAZ1 (Table 1), and bind with close to identical affinities (De Guzman et al., 2004; Berlow et al., 2017). Still, CITED2 outcompetes HIF-1 $\alpha$ for binding to TAZ1 (Berlow et al., 2017). The 
mechanism of this displacement has mainly been explained from detailed NMR studies (Berlow et al., 2017, 2019), according to which differences in the dynamic profiles on the pico- to nanosecond time scale of the bound TFs modulate competition for TAZ1. Both TFs fold upon binding to TAZ1, but HIF-1 $\alpha$ retains a high degree of flexibility in complex with TAZ1, while CITED2 uniformly rigidifies (Berlow et al., 2019). The dynamics particularly of the N-terminal region of bound HIF-1 $\alpha$ was suggested to allow CITED2 to access a key surface on TAZ1, promoting ternary complex formation and eventually displacement of HIF-1 $\alpha$. Simultaneously, the rigidification of key regions of CITED2 upon binding prevents HIF-1 $\alpha$ from back-competing (Figure 4). When characterizing TAZ1 in the free and bound states, the structure of TAZ1 was nearly identical in the HIF- $1 \alpha$ - and CITED2 bound states, but TAZ1 became more rigid in complex with CITED2. The rigidification occurred particularly in the binding region and regions undergoing conformational changes between HIF- $1 \alpha-$ and CITED2-bound states, suggesting tuning of TAZ1 backbone dynamics to discriminate between disordered partners (Berlow et al., 2019). Thus, backbone dynamics in folded hubs as well as their disordered partners play roles in partner selection and complex stability.

In combination, these studies have highlighted that the context of the inherent flexibility and dynamic properties of IDPs may allow for previously unknown binding- and competition mechanisms as well as bridge between the fast binding and high affinity needed in regulatory networks.

\section{Ensemble Redistribution and Allostery by Context} Correlated Fluctuations in Conformational Ensembles Emerging evidence suggests that the context of the ensemble of the entire IDP may be of key importance to understanding disorder-based interactions. Recently, new advanced applications of techniques such as fast field cycling (FFC) relaxometry (Parigi et al., 2014) and paramagnetic relaxation enhancement
(PRE) NMR spectroscopy (Kurzbach et al., 2016) have demonstrated the existence of correlated dynamics in IDPs over long sequential distances. Using FFC relaxometry, it was shown for four IDPs that slow reorientations on the several nanosecond time scale occurred in the chain, without specific residue interactions, but rather based on frictionmediated coupling (Parigi et al., 2014). Providing further details, a method based on PRE NMR, termed paramagnetic relaxation interference (PRI), allowed detection of correlated motions through covariance analysis of the effect of adding two paramagnetic labels to the same chain (Kurzbach et al., 2016, 2017). Utilizing this technique, Beier et al. (2018) showed that aSN and osteopontin display "energetic frustration" in their free states, which is the inability to fulfill conflicting energy requirements at the same time. Both proteins exhibited both correlated, anti-correlated and uncorrelated long-range chain fluctuations (Beier et al., 2018), with two residues being correlated if they display concerted motions or undergo simultaneous transitions between different conformational states, anti-correlated if they have anti-correlated fluctuations or structural changes due to, e.g., mutually exclusive conformational sub-states, and uncorrelated if they are independent. Interestingly, the correlation of motions changed for both IDPs upon partner binding (Beier et al., 2018). When the PRI analysis was performed on aSN bound to calmodulin and osteopontin bound to heparin, the anti-correlated fluctuations, or energetic couplings, of their free states were relieved. For aSN, this meant that sub-states of the aggregation-prone region were relieved of negative coupling, which the authors suggested may explain how calmodulin facilitates aggregation of aSN (Martinez et al., 2003).

\section{Regulation by Dynamic Allostery}

Proteins with energetically frustrated IDRs can mediate allosteric regulation (Garcia-Pino et al., 2010; Ferreon et al., 2013), which play a central role in orchestrating cellular signaling networks (Nussinov et al., 2013). Theoretical models for proteins

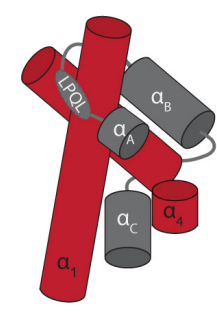

TAZ1: LPQL-HIF-1a

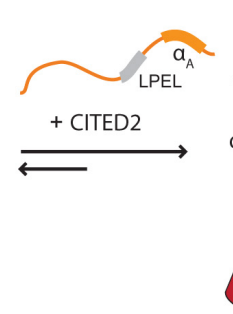

CITED2 2.... TAZ1: LPQL-HIF-1a

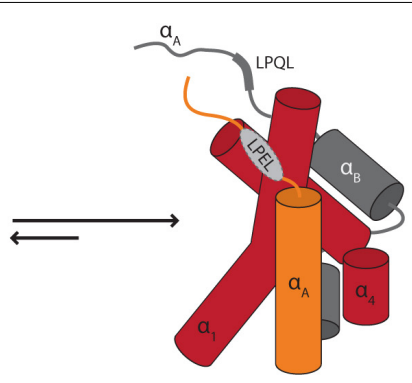

CITED2-LPEL :TAZ1 1....HIF-1a

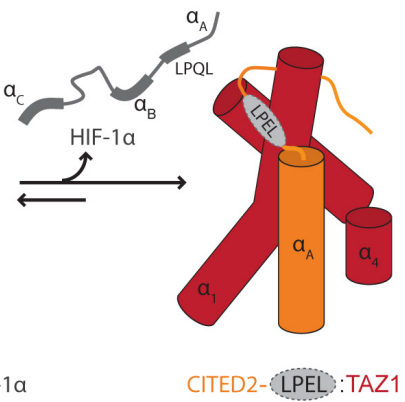

FIGURE 4 | Modulation of binding by chain dynamics. The flexible nature of HIF-1 $\alpha$ bound to TAZ1 allows the transactivation domain of CITED2 to gain access to TAZ1 through its $\mathrm{N}$-terminal region. This results in the formation of a ternary complex which induces an allosteric conformational change in TAZ1, disfavoring/out-competing HIF-1 $\alpha$ binding. The CITED2 LPEL-SLiM and flanking $\alpha_{A}$ helical region act cooperatively to displace HIF-1 $\alpha$ from the shared binding site for the $L P(Q / E) L$ SLiM and the restricted motions adopted in the bound state minimize competition for binding. In this schematic illustration, TAZ1 is depicted in red, $\mathrm{HIF-1} \alpha$ is dark gray and the bound LP(Q/E)L SLiM is light gray with a dashed outline. The SLiM-flanking regions in CITED2 are shown in orange. Adapted from Figure 4, originally published in Berlow et al. (2017). 
where at least one of the coupled sites is an IDR, assume that allosteric modulation is mediated via many conformers, where fluctuations among the conformers of one site can modulate the functional output of another site through energetic coupling (Hilser and Thompson, 2007) (Figure 1F). According to this allosteric ensemble model, the flexibility of disorder allows complex allosteric behavior of IDRs in fine-tuning regulatory interactions (Hilser and Thompson, 2007; Motlagh et al., 2014). The importance of such energetic frustration in IDP interactions has also been demonstrated from work on the glucocorticoid receptor (GR), where the disordered domain allosterically controls function by principles of energetic frustration (Li et al., 2018). GR has three domains: the C-terminal, folded DNA-binding domain (DBD), the disordered F-domain, and the N-terminal disordered R-domain. Binding of DNA to the DBD results in positive coupling to the F-domain ensemble, which is shifted toward stabilization of its folded form, in turn increasing its transcriptional activity. However, the DNA-bound DBD is also negatively coupled to the R-domain, shifting its ensemble to a state that destabilizes the F-domain. The net effect of DNA binding to the DBD on transcriptional activity of the full-length GR is hence a balance between the strength of the two couplings ( $\mathrm{Li}$ et al., 2018). Here, allostery is not an effect of a mechanical pathway between two sites, but rather by the energetic balance within the conformational ensemble, represented by changes in the population of states (Hilser and Thompson, 2007). Through this ensemble-mediated mechanism, multidomain proteins are suggested to exist in an ensemble of states poised to respond to binding. Binding leads to an ensemble redistribution, with a corresponding change of ensemble properties of the intact protein (Hilser and Thompson, 2007). For GR, signaling is tuned by changing the length of the intrinsically disordered context through translational isoforms, resulting in modulation of the degree of energetic frustration (Li et al., 2012, 2018).

Examples of flanking regions and chain contexts impacting binding by mechanisms involving dynamic allosteric regulation are accumulating. The competitive interactions of the TFs HIF$1 \alpha$ and CITED2 with the TAZ1 domain described in the previous section are for example an important demonstration of allosteric effects of SLiM flanking regions (Berlow et al., 2017, 2019) (Figure 1G). This example underscores how the dynamics and structure of the flanking regions of a SLiM may be even more important than the SLiM itself. For the plant TFs dehydration response element binding proteins 2A (DREB2A) and ANAC013, which both use the [DE]X[1,2][YF]X[1,4][DE] SLiM for binding to the cellular hub protein Radical Induced Cell Death1 (Bugge et al., 2018), disordered regions surrounding the binding motif exert positive and negative allosteric effects on binding, respectively (O'Shea et al., 2017) (Figure 1G and Table 1), possibly reflected in the function-related conservation of the disorder-order profiles for the NAC transcription factors (Stender et al., 2015). These effects could also be explained by the ensemble allosteric model as derived for GR. Thus, these examples show how flanking regions and chain contexts can contain sub-regions that are coupled to the SLiM, enabling allosteric modulation of the stability and accessibility of this site as well as adding avidity effects (Figures 1E-G).

\section{The Context of Phase Separation}

The formation of self-assembled, membrane-less organelles through liquid-liquid phase separation (LLPS) of proteins creates special contexts for IDP-based interactions and partitions with specific functions [for reviews, see Mitrea and Kriwacki (2016), Zaslavsky et al. (2018), Alberti et al. (2019)]. A SLiM may itself be necessary and responsible for leading IDPs into LLPS (Figure 1J), but conversely, LLPS may obstruct any other SLiM from engaging in interactions. The nucleolus, a membraneless compartment, is the site of ribosome biogenesis (Boisvert et al., 2007). Here, nucleophosmin (NPM1) is present at high concentrations, and, using its N-terminal domain, interacts with multiple other proteins via their Arg-rich SLiMs (R-motifs) (Figure 1J and Table 1) (Mitrea et al., 2014). Localization of NPM1 within nucleoli depends upon its ability to undergo LLPS with Arg-motif containing proteins and ribosomal RNA (Mitrea et al., 2016; Banani et al., 2017). Whereas a peptide derived from the ribosomal protein L5 (RPL5) with a single R-motif was sufficient for detectable binding to NPM1, at least two Argmotifs were needed for LLPS, demonstrating the need of Argmotif multivalency (Figure 1H) (Mitrea et al., 2016). Thus, the chain context contributes by increasing the number of motifs to establish different features that are not extractable from a single motif on its own.

Additional examples illustrate how IDRs with multiple interacting motifs can participate in LLPS mediated by weak multivalent interactions (Boija et al., 2018; Alberti et al., 2019). This is the case for, e.g., the activation domains of gene-specific TFs such as the yeast TF GCN4 (Boija et al., 2018). The activation activity of GCN4 depends on the SLiM ФФWФФLF (Table 1) (Warfield et al., 2014; Staby et al., 2017). However, this motif is part of a region with several hydrophobic patches, and GCN4 binds the Mediator co-activator component MED15 via multiple, low-affinity interactions, which additively contribute to activation activity (Drysdale et al., 1995; Warfield et al., 2014; Staller et al., 2018). Furthermore, for a mutant of GCN4 in which the aromatic residues of the hydrophobic patches were changed to Ala, incorporation into MED15 droplets was attenuated (Boija et al., 2018). Jointly, the results suggest that GCN4 and other TFs activate genes through the phase separating capacity of motif-centered, context regulated interactions by their activation domains (Boija et al., 2018).

In phase separation, the context of the disordered chain also has implications for interactions as explained by the stickers-and-spacers model of phase separation developed based on studies of RNA-binding proteins with prion-like domains (Wang et al., 2018; Martin et al., 2020). According to this model, the number (valence) of aromatic residues (stickers) and the patterning of the stickers, governed by the spacers, determine the phase behavior of prion-like domains to the extent that a numerical stickers-and-spacers model enables prediction of binodals/phase behavior from amino acid sequence (Martin et al., 2020). Future studies will have to show to 
BOX 1 | Outstanding questions.

- How do we differentiate and define SLiMs, flanking regions and chain context?

- How do we study and analyse the effects of flanking regions and chain context systematically?

- Are flanking regions and chain context evolutionary hot spots for hub interactions?

- Are flanking regions and chain context in some complexes more important in regulation than the SLiM itself?

- May flanking regions and chain context partake in new types of interaction mechanisms?

- Is chain dynamics an important contributor in interaction network fidelity?

- To which extent may IDP interactions be understood out of the full chain context?

what extent the stickers can be SLiMs, and not only individual residues, as well as reveal the characteristics of the spacers (Harmon et al., 2017).

\section{CONCLUSION AND OUTSTANDING QUESTIONS}

With the discovery of IDPs, the palette of interaction mechanisms is continuously expanding and forcing us to rethink protein interactions. Already in the 1970s, the importance of context in the understanding of proteins was formulated by Christian B. Anfinsen stating "that the native conformation is determined by the totality of interatomic interactions and hence by the amino acid sequence, in a given environment" (Anfinsen et al., 1961; Anfinsen, 1973). Thus, context has long been considered as part of the equation. For IDPs, the role of the environment, which is also its own disordered chain, may amplify due to their different properties compared to globular proteins. With a mouldable chain, context becomes broader than the chain itself, providing a much stronger contribution to regulation of disorder-based interactions. However, with the few examples highlighted in this paper, we need many more to be able to fully comprehend the role of the context in the orchestration of interactions involving IDPs. Hopefully, the present review has made it clear that the binding of many disordered proteins depends heavily on the context. Binding of many - if not all - SLiMs involves contributions from the flanking regions and/or the context. These contributions may be electrostatic in nature acting through dense regions of similar charges, either highly negatively charged, as for the flanks of the SLiM LxCxE of the $\mathrm{Rb}$ binding proteins (Palopoli et al., 2018), or highly positively charged as for the PCNA binding PIP-box (Prestel et al., 2019). However, the flanking regions may also have a highly hydrophobic character, as for the flanks of the [HKR]DEL SLiM (Alanen et al., 2011). Finally, the structure and dynamics of the flanks may be adding to competitions, cooperativity and allosteric regulation (Berlow et al., 2017; Li et al., 2017) as well as to ensure proper orientation and increase the speed of interaction, as discussed previously (Fuxreiter et al., 2007). In these cases, the role of the context and the flanking regions have been shown to modulate the affinity and have regulatory potential (Table $\mathbf{1}$ ). Indeed, as outlined above, there seems to be a surprising dependence of affinity and complex stability on the flanking regions. The thermodynamic details and structural requirements of flanking region interactions are largely unknown and represent an exciting challenge for the biophysical community.

Several questions remain outstanding (Box 1). The questions mainly address how interactions beyond the central contact points contribute to disorder-based interactions. Notably, the properties and importance of the flanking regions and of the disordered context have not been systematically addressed. Is it possible that our view on SLiMs is too restricted and that flanking regions or chain context should be considered as a true part of the motif and that they play roles in addition to modulation? Similarly, is it possible that context plays hitherto unrecognized roles as in, e.g., forming interactions in the unbound state to limit accessibility allosterically or participating in unrecognized mechanisms? Finally, have flanking regions and chain contexts developed to be meaningful for binding in those cases where a motif is overlapping/combined from several competing motifs? Once canonicity of a motif is lost, the flanking regions and the chain context could become evolutionary hot spots for maintaining binding to both - or more - partners. The examples in the present review testifies that work is being done to probe the effect of the context, but the journey has just begun. So, although we here highlighted the importance of flanking regions and the disordered chain properties in mediating regulatory function to IDP-based interactions, a huge knowledge void exists as to how these quantitatively and mechanistically contribute to binding, and more systematic studies as well as studies in vivo are highly warranted.

\section{AUTHOR CONTRIBUTIONS}

$\mathrm{KB}, \mathrm{IB}, \mathrm{CF}, \mathrm{JD}, \mathrm{JL}, \mathrm{JO}, \mathrm{KS}$, and BK contributed to the conceptual developments. JL, JD, CF, and IB contributed with first drafts of the paragraphs describing the external context and sequence properties, and the manuscript was written by $\mathrm{KB}, \mathrm{JO}, \mathrm{KS}$, and $\mathrm{BK}$ with input from and discussion with all authors.

\section{FUNDING}

This manuscript is a contribution from REPIN - rethinking protein interactions funded by the Novo Nordisk Foundation Challenge Program (Grant \#NNF18OC0033926).

\section{ACKNOWLEDGMENTS}

We thank all the former and present students of SBiNLab and REPIN working with IDPs for contributing with excellent questions and insights from their work. Asta Brandt Andersen is thanked for graphical contributions, and Peter Wright and Rebecca Berlow for sharing the graphical file for Figure 4. 


\section{REFERENCES}

Akhmanova, A., and Yap, A. S. (2008). Organizing junctions at the cell-cell interface. Cell 135, 791-793. doi: 10.1016/j.cell.2008.11.002

Alanen, H. I., Raykhel, I. B., Luukas, M. J., Salo, K. E. H., and Ruddock, L. W. (2011). Beyond KDEL: the role of positions 5 and 6 in determining ER localization. J. Mol. Biol. 409, 291-297. doi: 10.1016/j.jmb.2011.03.070

Alberti, S., Gladfelter, A., and Mittag, T. (2019). Considerations and challenges in studying liquid-liquid phase separation and biomolecular condensates. Cell 176, 419-434. doi: 10.1016/j.cell.2018.12.035

Anfinsen, C. B. (1973). Principles that govern the folding of protein chains. Science 181, 223-230. doi: 10.1126/science.181.4096.223

Anfinsen, C. B., Haber, E., Sela, M., and White, F. H. (1961). The kinetics of formation of native ribonuclease during oxidation of the reduced polypeptide chain. Proc. Natl. Acad. Sci. U.S.A. 47, 1309-1314. doi: 10.1073/pnas.47.9.1309

Bah, A., and Forman-Kay, J. D. (2016). Modulation of intrinsically disordered protein function by post-translational modifications. J. Biol. Chem. 291, 66966705. doi: 10.1074/jbc.R115.695056

Bah, A., Vernon, R. M., Siddiqui, Z., Krzeminski, M., Muhandiram, R., Zhao, C., et al. (2015). Folding of an intrinsically disordered protein by phosphorylation as a regulatory switch. Nature 519, 106-109. doi: 10.1038/nature13999

Banani, S. F., Lee, H. O., Hyman, A. A., and Rosen, M. K. (2017). Biomolecular condensates: organizers of cellular biochemistry. Nat. Rev. Mol. Cell Biol. 18, 285-298. doi: 10.1038/nrm.2017.7

Beier, A., Schwarz, T. C., Kurzbach, D., Platzer, G., Tribuzio, F., and Konrat, R. (2018). Modulation of correlated segment fluctuations in IDPs upon complex formation as an allosteric regulatory mechanism. J. Mol. Biol. 430, 2439-2452. doi: 10.1016/j.jmb.2018.04.035

Bell-Pedersen, D., Cassone, V. M., Earnest, D. J., Golden, S. S., Hardin, P. E., Thomas, T. L., et al. (2005). Circadian rhythms from multiple oscillators: lessons from diverse organisms. Nat. Rev. Genet. 6, 544-556. doi: 10.1038/nrg1633

Berlow, R. B., Dyson, H. J., and Wright, P. E. (2017). Hypersensitive termination of the hypoxic response by a disordered protein switch. Nature 543, 447-451. doi: 10.1038/nature21705

Berlow, R. B., Martinez-yamout, M. A., Dyson, H. J., and Wright, P. E. (2019). Role of backbone dynamics in modulating the interactions of disordered ligands with the TAZ1 domain of the CREB-binding protein. Biochemistry 58, 1354-1362. doi: 10.1021/acs.biochem.8b01290

Boija, A., Klein, I. A., Sabari, B. R., Dall'Agnese, A., Coffey, E. L., Zamudio, A. V., et al. (2018). Transcription factors activate genes through the phase-separation capacity of their activation domains. Cell 175, 1842-1855.e16. doi: 10.1016/j. cell.2018.10.042

Boisvert, F.-M., van Koningsbruggen, S., Navascués, J., and Lamond, A. I. (2007). The multifunctional nucleolus. Nat. Rev. Mol. Cell Biol. 8, 574-585. doi: 10. 1038/nrm 2184

Borcherds, W., Theillet, F. X., Katzer, A., Finzel, A., Mishall, K. M., Powell, A. T., et al. (2014). Disorder and residual helicity alter p53-Mdm2 binding affinity and signaling in cells. Nat. Chem. Biol. 10, 1000-1002. doi: 10.1038/nchembio.1668

Borgia, A., Borgia, M. B., Bugge, K., Kissling, V. M., Heidarsson, P. O., Fernandes, C. B., et al. (2018). Extreme disorder in an ultrahigh-affinity protein complex. Nature 555, 61-66. doi: 10.1038/nature25762

Bräuer, P., Parker, J. L., Gerondopoulos, A., Zimmermann, I., Seeger, M. A., Barr, F. A., et al. (2019). Structural basis for $\mathrm{pH}$-dependent retrieval of ER proteins from the Golgi by the KDEL receptor. Science 363, 1103-1107. doi: 10.1126/ science.aaw2859

Bugge, K., Staby, L., Kemplen, K. R., O’Shea, C., Bendsen, S. K., Jensen, M. K., et al. (2018). Structure of radical-induced cell death1 hub domain reveals a common $\alpha \alpha$-scaffold for disorder in transcriptional networks. Structure 26, 734-746.e7. doi: 10.1016/j.str.2018.03.013

Cafarelli, T. M., Desbuleux, A., Wang, Y., Choi, S. G., De Ridder, D., and Vidal, M. (2017). Mapping, modeling, and characterization of protein-protein interactions on a proteomic scale. Curr. Opin. Struct. Biol. 44, 201-210. doi: 10.1016/j.sbi.2017.05.003

Casey, J. R., Grinstein, S., and Orlowski, J. (2010). Sensors and regulators of intracellular pH. Nat. Rev. Mol. Cell Biol. 11, 50-61. doi: 10.1038/nrm2820

Chen, Y., Wang, P., and Slep, K. C. (2019). Mapping multivalency in the CLIP-170EB1 microtubule plus-end complex. J. Biol. Chem. 294, 918-931. doi: 10.1074/ jbc.RA118.006125
Chenal, A., Guijarro, J. I., Raynal, B., Delepierre, M., and Ladant, D. (2009). RTX calcium binding motifs are intrinsically disordered in the absence of calcium: implication for protein secretion. J. Biol. Chem. 284, 1781-1789. doi: 10.1074/ jbc.M807312200

Cholak, E., Bugge, K., Khondker, A., Gauger, K., Pedraz-Cuesta, E., Pedersen, M. E., et al. (2020). Avidity within the N-terminal anchor drives $\alpha$-synuclein membrane interaction and insertion. FASEB J. doi: 10.1096/fj.202000107r [Epub ahead of print].

Christensen, L. F., Staby, L., Bugge, K., O’Shea, C., Kragelund, B. B., and Skriver, K. (2019). Evolutionary conservation of the intrinsic disorder-based RadicalInduced Cell Death1 hub interactome. Sci. Rep. 9:18927. doi: 10.1038/s41598019-55385-3

Clark, S., Myers, J. B., King, A., Fiala, R., Novacek, J., Pearce, G., et al. (2018). Multivalency regulates activity in an intrinsically disordered transcription factor. eLife 7:e36258. doi: 10.7554/eLife.36258

Clark, S., Nyarko, A., Löhr, F., Karplus, P. A., and Barbar, E. (2016). The anchored flexibility model in LC8 motif recognition: insights from the chica complex. Biochemistry 55, 199-209. doi: 10.1021/acs.biochem.5b01099

Clark, S. A., Jespersen, N., Woodward, C., and Barbar, E. (2015). Multivalent IDP assemblies: unique properties of LC8-associated, IDP duplex scaffolds. FEBS Lett. 589, 2543-2551. doi: 10.1016/j.febslet.2015.07.032

Costello, J. L., Castro, I. G., Camões, F., Schrader, T. A., McNeall, D., Yang, J., et al. (2017). Predicting the targeting of tail-anchored proteins to subcellular compartments in mammalian cells. J. Cell Sci. 130, 1675-1687. doi: 10.1242/jcs. 200204

Cragnell, C., Staby, L., Lenton, S., Kragelund, B., and Skepö, M. (2019). Dynamical oligomerisation of histidine rich intrinsically disordered proteins is regulated through zinc-histidine interactions. Biomolecules 9:E168. doi: 10. 3390/biom9050168

Das, R. K., Huang, Y., Phillips, A. H., Kriwacki, R. W., and Pappu, R. V. (2016). Cryptic sequence features within the disordered protein p27Kip1 regulate cell cycle signaling. Proc. Natl. Acad. Sci. U.S.A. 113, 5616-5621. doi: 10.1073/pnas. 1516277113

Das, R. K., and Pappu, R. V. (2013). Conformations of intrinsically disordered proteins are influenced by linear sequence distributions of oppositely charged residues. Proc. Natl. Acad. Sci. U.S.A. 110, 13392-13397. doi: 10.1073/pnas. 1304749110

Das, R. K., Ruff, K. M., and Pappu, R. V. (2015). Relating sequence encoded information to form and function of intrinsically disordered proteins. Curr. Opin. Struct. Biol. 32, 102-112. doi: 10.1016/j.sbi.2015.03.008

Davey, N. E., Cyert, M. S., and Moses, A. M. (2015). Short linear motifs - ex nihilo evolution of protein regulation. Cell Commun. Signal. 13:43. doi: 10.1186/ s12964-015-0120-z

Davey, N. E., Van Roey, K., Weatheritt, R. J., Toedt, G., Uyar, B., Altenberg, B., et al. (2012). Attributes of short linear motifs. Mol. Biosyst. 8, 268-281. doi: $10.1039 / \mathrm{clmb} 05231 \mathrm{~d}$

De Avila, M., Vassall, K. A., Smith, G. S. T., Bamm, V. V., and Harauz, G. (2014). The proline-rich region of $18.5 \mathrm{kDa}$ myelin basic protein binds to the $\mathrm{SH} 3-$ domain of Fyn tyrosine kinase with the aid of an upstream segment to form a dynamic complex in vitro. Biosci. Rep. 34:e00157. doi: 10.1042/BSR20140149

De Guzman, R. N., Martinez-Yamout, M. A., Dyson, H. J., and Wright, P. E. (2004). Interaction of the TAZ1 domain of the CREB-binding protein with the activation domain of CITED2: regulation by competition between intrinsically unstructured ligands for non-identical binding sites. J. Biol. Chem. 279, 30423049. doi: 10.1074/jbc.M310348200

Doray, B., Ghosh, P., Griffith, J., Geuze, H. J., and Kornfeld, S. (2002). Cooperation of GGAs and AP-1 in packaging MPRs at the trans-Golgi network. Science 297, 1700-1703. doi: 10.1126/science.1075327

Dosztányi, Z., Chen, J., Dunker, A. K., Simon, I., and Tompa, P. (2006). Disorder and sequence repeats in hub proteins and their implications for network evolution. J. Proteome Res. 5, 2985-2995. doi: 10.1021/pr060171o

Drysdale, C. M., Dueñas, E., Jackson, B. M., Reusser, U., Braus, G. H., and Hinnebusch, A. G. (1995). The transcriptional activator GCN4 contains multiple activation domains that are critically dependent on hydrophobic amino acids. Mol. Cell. Biol. 15, 1220-1233. doi: 10.1128/mcb.15.3.1220

Ferreon, A. C. M., Ferreon, J. C., Wright, P. E., and Deniz, A. A. (2013). Modulation of allostery by protein intrinsic disorder. Nature 498, 390-394. doi: 10.1038/ nature 12294 
Furuita, K., Jee, J., Fukada, H., Mishima, M., and Kojima, C. (2010). Electrostatic interaction between oxysterol-binding protein and VAMP-associated protein A revealed by NMR and mutagenesis studies. J. Biol. Chem. 285, 12961-12970. doi: 10.1074/jbc.M109.082602

Fusco, G., De Simone, A., Gopinath, T., Vostrikov, V., Vendruscolo, M., Dobson, C. M., et al. (2014). Direct observation of the three regions in $\alpha$-synuclein that determine its membrane-bound behaviour. Nat. Commun. 5:3827. doi: $10.1038 /$ ncomms 4827

Fuxreiter, M. (2019). Fold or not to fold upon binding - does it really matter? Curr. Opin. Struct. Biol. 54, 19-25. doi: 10.1016/j.sbi.2018.09.008

Fuxreiter, M., Tompa, P., and Simon, I. (2007). Local structural disorder imparts plasticity on linear motifs. Bioinformatics 23, 950-956. doi: 10.1093/ bioinformatics/btm035

Garcia-Pino, A., Balasubramanian, S., Wyns, L., Gazit, E., De Greve, H., Magnuson, R. D., et al. (2010). Allostery and intrinsic disorder mediate transcription regulation by conditional cooperativity. Cell 142, 101-111. doi: 10.1016/j.cell. 2010.05.039

Garg, A., Orru, R., Ye, W., Distler, U., Chojnacki, J. E., Köhn, M., et al. (2019). Structural and mechanistic insights into the interaction of the circadian transcription factor BMAL1 with the KIX domain of the CREB-binding protein. J. Biol. Chem. 294, 16604-16619. doi: 10.1074/jbc.RA119.009845

Gekakis, N., Staknis, D., Nguyen, H. B., Davis, F. C., Wilsbacher, L. D., King, D. P., et al. (1998). Role of the CLOCK protein in the mammalian circadian mechanism. Science 280, 1564-1569. doi: 10.1126/science.280.5369.1564

Georgieva, E. R., Ramlall, T. F., Borbat, P. P., Freed, J. H., and Eliezer, D. (2008). Membrane-bound $\alpha$-synuclein forms an extended helix: long-distance pulsed ESR measurements using vesicles, bicelles, and rodlike micelles. J. Am. Chem. Soc. 130, 12856-12857. doi: 10.1021/ja804517m

Gilljam, K. M., Feyzi, E., Aas, P. A., Sousa, M. M. L., Müller, R., Vågbø, C. B., et al. (2009). Identification of a novel, widespread, and functionally important PCNA-binding motif. J. Cell Biol. 186, 645-654. doi: 10.1083/jcb.200903138

Gorelik, M., and Davidson, A. R. (2012). Distinct peptide binding specificities of Src Homology 3 (SH3) protein domains can be determined by modulation of local energetics across the binding interface. J. Biol. Chem. 287, 9168-9177. doi: 10.1074/jbc.M111.330753

Gustafson, C. L., Parsley, N. C., Asimgil, H., Davis, T. L., Liu, A. C., Partch, C. L., et al. (2017). A slow conformational switch in the BMAL1 transactivation domain modulates circadian article a slow conformational switch in the BMAL1 transactivation domain modulates circadian rhythms. Mol. Cell 66, 447-457.e7. doi: 10.1016/j.molcel.2017.04.011

Hansen, J. C., Tse, C., and Wolffe, A. P. (1998). Structure and function of the core histone N-termini: more than meets the eye. Biochemistry 37, 17637-17641. doi: $10.1021 /$ bi $982409 \mathrm{v}$

Harauz, G., Ladizhansky, V., and Boggs, J. M. (2009). Structural polymorphism and multifunctionality of myelin basic protein. Biochemistry 48, 8094-8104. doi: 10.1021/bi901005f

Harmon, T. S., Holehouse, A. S., Rosen, M. K., and Pappu, R. V. (2017). Intrinsically disordered linkers determine the interplay between phase separation and gelation in multivalent proteins. eLife 6:e30294. doi: 10.7554/ eLife.30294

Havens, C. G., and Walter, J. C. (2009). Docking of a specialized PIP Box onto chromatin-bound PCNA creates a degron for the ubiquitin ligase CRL4Cdt2. Mol. Cell 35, 93-104. doi: 10.1016/j.molcel.2009.05.012

Heery, D. M., Kalkhoven, E., Hoare, S., and Parker, M. G. (1997). A signature motif in transcriptional co-activators mediates binding to nuclear receptors. Nature 387, 733-736. doi: 10.1038/42750

Heilker, R., Spiess, M., and Crottet, P. (1999). Recognition of sorting signals by clathrin adaptors. Bioessays 21, 558-567. doi: 10.1002/(sici)1521-1878(199907) 21:7<558::aid-bies4>3.0.co;2-r

Hendus-Altenburger, R., Fernandes, C. B., Bugge, K., Kunze, M. B. A., Boomsma, W., and Kragelund, B. B. (2019). Random coil chemical shifts for serine, threonine and tyrosine phosphorylation over a broad $\mathrm{pH}$ range. J. Biomol. NMR 73, 713-725. doi: 10.1007/s10858-019-00283-Z

Hendus-Altenburger, R., Kragelund, B. B., and Pedersen, S. F. (2014). Structural dynamics and regulation of the mammalian SLC9A family of $\mathrm{Na}+\mathrm{H}+$ exchangers. Curr. Top. Membr. 73, 69-148. doi: 10.1016/B978-0-12-800223$0.00002-5$
Hendus-Altenburger, R., Lambrughi, M., Terkelsen, T., Pedersen, S. F., Papaleo, E., Lindorff-Larsen, K., et al. (2017). A phosphorylation-motif for tuneable helix stabilisation in intrinsically disordered proteins - Lessons from the sodium proton exchanger 1 (NHE1). Cell. Signal. 37, 40-51. doi: 10.1016/j.cellsig.2017. 05.015

Hertz, E. P. T., Kruse, T., Davey, N. E., López-Méndez, B., Sigurð̋sson, J. O., Montoya, G., et al. (2016). A conserved motif provides binding specificity to the PP2A-B56 phosphatase. Mol. Cell 63, 686-695. doi: 10.1016/j.molcel.2016. 06.024

Hilser, V. J., and Thompson, E. B. (2007). Intrinsic disorder as a mechanism to optimize allosteric coupling in proteins. Proc. Natl. Acad. Sci. U.S.A. 104, 8311-8315. doi: 10.1073/pnas.0700329104

Hough, L. E., Dutta, K., Sparks, S., Temel, D. B., Kamal, A., TetenbaumNovatt, J., et al. (2015). The molecular mechanism of nuclear transport revealed by atomic-scale measurements. eLife 4:e10027. doi: 10.7554/eLife. 10027

Hsiao, H.-C., Gonzalez, K. L., Catanese, D. J., Jordy, K. E., Matthews, K. S., and Bondos, S. E. (2014). The intrinsically disordered regions of the Drosophila melanogaster Hox protein ultrabithorax select interacting proteins based on partner topology. PLoS One 9:e108217. doi: 10.1371/journal.pone. 0108217

Huang, N., Chelliah, Y., Shan, Y., Taylor, C. A., Yoo, S.-H., Partch, C., et al. (2012). Crystal structure of the heterodimeric CLOCK:BMAL1 transcriptional activator complex. Science 337, 189-194. doi: 10.1126/science.1222804

Iakoucheva, L. M., Radivojac, P., Brown, C. J., O'Connor, T. R., Sikes, J. G., Obradovic, Z., et al. (2004). The importance of intrinsic disorder for protein phosphorylation. Nucleic Acids Res. 32, 1037-1049. doi: 10.1093/nar/gkh253

Iešmantavičius, V., Dogan, J., Jemth, P., Teilum, K., and Kjaergaard, M. (2014). Helical propensity in an intrinsically disordered protein accelerates ligand binding. Angew. Chem. Int. Ed. Engl. 53, 1548-1551. doi: 10.1002/anie. 201307712

Ivarsson, Y., and Jemth, P. (2019). Affinity and specificity of motif-based proteinprotein interactions. Curr. Opin. Struct. Biol. 54, 26-33. doi: 10.1016/j.sbi.2018. 09.009

Jiang, K., Toedt, G., Montenegro Gouveia, S., Davey, N. E., Hua, S., van der Vaart, B., et al. (2012). A Proteome-wide screen for mammalian SxIP motifcontaining microtubule plus-end tracking proteins. Curr. Biol. 22, 1800-1807. doi: 10.1016/j.cub.2012.07.047

Jones, R. E., Wegrzyn, R. J., Patrick, D. R., Balishin, N. L., Vuocolo, G. A., Riemen, M. W., et al. (1990). Identification of HPV-16 E7 peptides that are potent antagonists of E7 binding to the retinoblastoma suppressor protein. J. Biol. Chem. 265, 12782-12785.

Kaiser, S. E., Brickner, J. H., Reilein, A. R., Fenn, T. D., Walter, P., and Brunger, A. T. (2005). Structural basis of FFAT motif-mediated ER targeting. Structure 13, 1035-1045. doi: 10.1016/j.str.2005.04.010

Kelil, A., Levy, E. D., and Michnick, S. W. (2016). Evolution of domain-peptide interactions to coadapt specificity and affinity to functional diversity. Proc. Natl. Acad. Sci. U.S.A. 113, E3862-E3871. doi: 10.1073/pnas.1518469113

Kelly, B. T., McCoy, A. J., Späte, K., Miller, S. E., Evans, P. R., Höning, S., et al. (2008). A structural explanation for the binding of endocytic dileucine motifs by the AP2 complex. Nature 456, 976-979. doi: 10.1038/nature07422

Knudsen, E. S., and Wang, J. Y. (1996). Differential regulation of retinoblastoma protein function by specific Cdk phosphorylation sites. J. Biol. Chem. 271, 8313-8320. doi: 10.1074/jbc.271.14.8313

Kragelund, B. B., and Skriver, K. (2020). Methods in Molecular Biology: Intrinsically Disordered Proteins, ed. J. Walker (Berlin: Springer).

Krystkowiak, I., and Davey, N. E. (2017). SLiMSearch: a framework for proteomewide discovery and annotation of functional modules in intrinsically disordered regions. Nucleic Acids Res. 45, W464-W469. doi: 10.1093/nar/gkx238

Kurzbach, D., Beier, A., Vanas, A., Flamm, A. G., Platzer, G., Schwarz, T. C., et al. (2017). NMR probing and visualization of correlated structural fluctuations in intrinsically disordered proteins. Phys. Chem. Chem. Phys. 19, 10651-10656. doi: $10.1039 / \mathrm{c} 7 \mathrm{cp} 00430 \mathrm{c}$

Kurzbach, D., Vanas, A., Flamm, A. G., Tarnoczi, N., Kontaxis, G., Maltar-Strmečki, N., et al. (2016). Detection of correlated conformational fluctuations in intrinsically disordered proteins through paramagnetic relaxation interference. Phys. Chem. Chem. Phys. 18, 5753-5758. doi: 10.1039/c5cp04858c 
Lee, C., Kalmar, L., Xue, B., Tompa, P., Daughdrill, G. W., Uversky, V. N., et al. (2014). Contribution of proline to the pre-structuring tendency of transient helical secondary structure elements in intrinsically disordered proteins. Biochim. Biophys. Acta 1840, 993-1003. doi: 10.1016/j.bbagen.2013.10.042

Lee, S.-H., Kim, D.-H., Han, J. J., Cha, E.-J., Lim, J.-E., Cho, Y.-J., et al. (2012). Understanding pre-structured motifs (PreSMos) in intrinsically unfolded proteins. Curr. Protein Pept. Sci. 13, 34-54. doi: 10.2174/13892031279927 7974

Li, J., Motlagh, H. N., Chakuroff, C., Thompson, E. B., and Hilser, V. J. (2012). Thermodynamic dissection of the intrinsically disordered N-terminal domain of human glucocorticoid receptor. J. Biol. Chem. 287, 26777-26787. doi: 10. 1074/jbc.M112.355651

Li, J., White, J. T., Saavedra, H., Wrabl, J. O., Motlagh, H. N., Liu, K., et al. (2017). Genetically tunable frustration controls allostery in an intrinsically disordered transcription factor. eLife 6:e30688. doi: 10.7554/eLife.30688

Li, J., White, J. T., Saavedra, H., Wrabl, J. O., Motlagh, H. N., Liu, K., et al. (2018). Genetically tunable frustration controls allostery in an intrinsically disordered transcription factor. eLife 7:e35768. doi: 10.7554/eLife.35768

Liu, Y., Huang, A., Booth, R. M., Mendes, G. G., Merchant, Z., Matthews, K. S., et al. (2018). Evolution of the activation domain in a Hox transcription factor. Int. J. Dev. Biol. 62, 745-753. doi: 10.1387/ijdb.180151sb

Locasale, J. W. (2008). Allovalency revisited: an analysis of multisite phosphorylation and substrate rebinding. J. Chem. Phys. 128:115106. doi: 10.1063/1.2841124

Loewen, C. J. R., Roy, A., and Levine, T. P. (2003). A conserved ER targeting motif in three families of lipid binding proteins and in Opilp binds VAP. EMBO J. 22, 2025-2035. doi: 10.1093/emboj/cdg201

López, A. J., Artero, R. D., and Pérez-Alonso, M. (1996). Stage, tissue, and cell specific distribution of alternative Ultrabithorax mRNAs and protein isoforms in the Drosophila embryo. Roux's Arch. Dev. Biol. 205, 450-459. doi: 10.1007/ BF00377226

Lowe, R., Pountney, D. L., Jensen, P. H., Gai, W. P., and Voelcker, N. H. (2004). Calcium(II) selectively induces alpha-synuclein annular oligomers via interaction with the C-terminal domain. Protein Sci. 13, 3245-3252. doi: 10. 1110/ps.04879704

Majava, V., Petoukhov, M. V., Hayashi, N., Pirilä, P., Svergun, D. I., and Kursula, P. (2008). Interaction between the C-terminal region of human myelin basic protein and calmodulin: analysis of complex formation and solution structure. BMC Struct. Biol. 8:10. doi: 10.1186/1472-6807-8-10

Majoul, I., Straub, M., Hell, S. W., Duden, R., and Söling, H. D. (2001). KDELcargo regulates interactions between proteins involved in COPI vesicle traffic: measurements in living cells using FRET. Dev. Cell 1, 139-153. doi: 10.1016/ s1534-5807(01)00004-1

Malhis, N., and Gsponer, J. (2015). Computational identification of MoRFs in protein sequences. Bioinformatics 31, 1738-1744. doi: 10.1093/bioinformatics/ btv060

Mao, A. H., Lyle, N., and Pappu, R. V. (2013). Describing sequence-ensemble relationships for intrinsically disordered proteins. Biochem. J. 449, 307-318. doi: 10.1042/BJ20121346

Marsh, J. A., and Forman-kay, J. D. (2010). Sequence determinants of compaction in intrinsically disordered proteins. Biophys. J. 98, 2383-2390. doi: 10.1016/j. bpj.2010.02.006

Martin, E. W., Holehouse, A. S., Grace, C. R., Hughes, A., Pappu, R. V., and Mittag, T. (2016). Sequence determinants of the conformational properties of an intrinsically disordered protein prior to and upon multisite phosphorylation. J. Am. Chem. Soc. 138, 15323-15335. doi: 10.1021/jacs.6b10272

Martin, E. W., Holehouse, A. S., Peran, I., Farag, M., Incicco, J. J., Bremer, A., et al. (2020). Valence and patterning of aromatic residues determine the phase behavior of prion-like domains. Science 367, 694-699. doi: 10.1126/science. aaw8653

Martinez, J., Moeller, I., Erdjument-Bromage, H., Tempst, P., and Lauring, B. (2003). Parkinson's disease-associated $\alpha$-synuclein is a calmodulin substrate. J. Biol. Chem. 278, 17379-17387. doi: 10.1074/jbc.M209020200

Mei, M., Zhai, C., Li, X., Zhou, Y., Peng, W., Ma, L., et al. (2017). Characterization of aromatic residue-controlled protein retention in the endoplasmic reticulum of Saccharomyces cerevisiae. J. Biol. Chem. 292, 20707-20719. doi: 10.1074/jbc. M117.812107
Meyer, K., Kirchner, M., Uyar, B., Cheng, J.-Y., Russo, G., Hernandez-Miranda, L. R., et al. (2018). Mutations in disordered regions can cause disease by creating dileucine motifs. Cell 175, 239-253.e17. doi: 10.1016/j.cell.2018.08.019

Milles, S., Mercadante, D., Aramburu, I. V., Jensen, M. R., Banterle, N., Koehler, C., et al. (2015). Plasticity of an ultrafast interaction between nucleoporins and nuclear transport receptors. Cell 163, 734-745. doi: 10.1016/j.cell.2015. 09.047

Misra, S., Puertollano, R., Kato, Y., Bonifacino, J. S., and Hurley, J. H. (2002). Structural basis for acidic-cluster-dileucine sorting-signal recognition by VHS domains. Nature 415, 933-937. doi: 10.1038/41 $5933 \mathrm{a}$

Mitrea, D. M., Cika, J. A., Guy, C. S., Ban, D., Banerjee, P. R., Stanley, C. B., et al. (2016). Nucleophosmin integrates within the nucleolus via multi-modal interactions with proteins displaying R-rich linear motifs and rRNA. eLife 5:e13571. doi: 10.7554/eLife.13571

Mitrea, D. M., Grace, C. R., Buljan, M., Yun, M.-K., Pytel, N. J., Satumba, J., et al. (2014). Structural polymorphism in the N-terminal oligomerization domain of NPM1. Proc. Natl. Acad. Sci. U.S.A. 111, 4466-4471. doi: 10.1073/pnas. 1321007111

Mitrea, D. M., and Kriwacki, R. W. (2016). Phase separation in biology; functional organization of a higher order. Cell Commun. Signal. 14:1. doi: 10.1186/s12964015-0125-7

Mittag, T., Orlicky, S., Choy, W.-Y., Tang, X., Lin, H., Sicheri, F., et al. (2008). Dynamic equilibrium engagement of a polyvalent ligand with a single-site receptor. Proc. Natl. Acad. Sci. U.S.A. 105, 17772-17777. doi: 10.1073/pnas. 0809222105

Moldovan, G.-L., Pfander, B., and Jentsch, S. (2007). PCNA, the maestro of the replication fork. Cell 129, 665-679. doi: 10.1016/j.cell.2007.05.003

Mosca, R., Céol, A., and Aloy, P. (2013). Interactome3D: adding structural details to protein networks. Nat. Methods 10, 47-53. doi: 10.1038/nmeth. 2289

Motlagh, H. N., Wrabl, J. O., Li, J., and Hilser, V. J. (2014). The ensemble nature of allostery. Nature 508, 331-339. doi: 10.1038/nature13001

Muller-Spath, S., Soranno, A., Hirschfeld, V., Hofmann, H., Ruegger, S., Reymond, L., et al. (2010). Charge interactions can dominate the dimensions of intrinsically disordered proteins. Proc. Natl. Acad. Sci. U.S.A. 107, 14609-14614. doi: 10.1073/pnas.1001743107

Munishkina, L. A., Fink, A. L., and Uversky, V. N. (2004). Conformational prerequisites for formation of amyloid fibrils from histones. J. Mol. Biol. 342, 1305-1324. doi: 10.1016/j.jmb.2004.06.094

Murphy, S. E., and Levine, T. P. (2016). VAP, a versatile access point for the endoplasmic reticulum: review and analysis of FFAT-like motifs in the VAPome. Biochim. Biophys. Acta 1861, 952-961. doi: 10.1016/j.bbalip.2016.02.009

Mylona, A., Theillet, F.-X., Foster, C., Cheng, T. M., Miralles, F., Bates, P. A., et al. (2016). Opposing effects of Elk-1 multisite phosphorylation shape its response to ERK activation. Science 354, 233-237. doi: 10.1126/science.aad 1872

Nørholm, A., Hendus-Altenburger, R., Bjerre, G., Kjaergaard, M., Pedersen, S. F., and Kragelund, B. B. (2011). The intracellular distal tail of the $\mathrm{Na}+\mathrm{H}+$ exchanger NHE1 is intrinsically disordered: implications for NHE1 trafficking. Biochemistry 50, 3469-3480. doi: 10.1021/bi1019989

Noval, M. G., Gallo, M., Perrone, S., Salvay, A. G., Chemes, L. B., and de Prat-Gay, G. (2013). Conformational dissection of a viral intrinsically disordered domain involved in cellular transformation. PLoS One 8:e72760. doi: 10.1371/journal. pone. 0072760

Nussinov, R., Tsai, C.-J., and Ma, B. (2013). The underappreciated role of allostery in the cellular network. Annu. Rev. Biophys. 42, 169-189. doi: 10.1146/annurevbiophys-083012-130257

O’Brien, D. P., Perez, A. C. S., Karst, J., Cannella, S. E., Enguéné, V. Y. N., Hessel, A., et al. (2018). Calcium-dependent disorder-to-order transitions are central to the secretion and folding of the CyaA toxin of Bordetella pertussis, the causative agent of whooping cough. Toxicon 149, 37-44. doi: 10.1016/j.toxicon.2018.01. 007

Ohgaki, R., van IJzendoorn, S. C. D., Matsushita, M., Hoekstra, D., and Kanazawa, H. (2011). Organellar $\mathrm{Na}+/ \mathrm{H}+$ exchangers: novel players in organelle $\mathrm{pH}$ regulation and their emerging functions. Biochemistry 50, 443-450. doi: 10 . 1021/bi101082e 
Oldfield, C. J., Meng, J., Yang, J. Y., Yang, M. Q., Uversky, V. N., and Dunker, A. K. (2008). Flexible nets: disorder and induced fit in the associations of p53 and 143-3 with their partners. BMC Genomics 9(Suppl. 1):S1. doi: 10.1186/1471-21649-S1-S1

O’Shea, C., Staby, L., Bendsen, S. K., Tidemand, F. G., Redsted, A., Willemoës, M., et al. (2017). Structures and short linear motif of disordered transcription factor regions provide clues to the interactome of the cellular hub protein radical-induced cell death 1. J. Biol. Chem. 292, 512-527. doi: 10.1074/jbc.M116. 753426

Palopoli, N., González Foutel, N. S., Gibson, T. J., and Chemes, L. B. (2018). Short linear motif core and flanking regions modulate retinoblastoma protein binding affinity and specificity. Protein Eng. Des. Sel. 31, 69-77. doi: 10.1093/protein/ gzx068

Parigi, G., Rezaei-Ghaleh, N., Giachetti, A., Becker, S., Fernandez, C., Blackledge, M., et al. (2014). Long-range correlated dynamics in intrinsically disordered proteins. J. Am. Chem. Soc. 136, 16201-16209. doi: 10.1021/ja50 $6820 \mathrm{r}$

Partch, C. L., Green, C. B., and Takahashi, J. S. (2014). Molecular architecture of the mammalian circadian clock. Trends Cell Biol. 24, 90-99. doi: 10.1016/j.tcb. 2013.07.002

Pedersen, S. F., and Counillon, L. (2019). The SLC9A-C mammalian Na+/H+ exchanger family: molecules, mechanisms, and physiology. Physiol. Rev. 99, 2015-2113. doi: 10.1152/physrev.00028.2018

Polverini, E., Fasano, A., Zito, F., Riccio, P., and Cavatorta, P. (1999). Conformation of bovine myelin basic protein purified with bound lipids. Eur. Biophys. J. 28, 351-355. doi: 10.1007/s0024900 50218

Prasad, H., and Rao, R. (2015). The Na+/H+ exchanger NHE6 modulates endosomal $\mathrm{pH}$ to control processing of amyloid precursor protein in a cell culture model of Alzheimer disease. J. Biol. Chem. 290, 5311-5327. doi: 10.1074/ jbc.M114.602219

Prestel, A., Wichmann, N., Martins, J. M., Marabini, R., Kassem, N., Broendum, S. S., et al. (2019). The PCNA interaction motifs revisited: thinking outside the PIP-box. Cell. Mol. Life Sci. 76, 4923-4943. doi: 10.1007/s00018-01903150-0

Raasakka, A., Jones, N. C., Hoffmann, S. V., and Kursula, P. (2019). Ionic strength and calcium regulate membrane interactions of myelin basic protein and the cytoplasmic domain of myelin protein zero. Biochem. Biophys. Res. Commun. 511, 7-12. doi: 10.1016/j.bbrc.2019.02.025

Ranaldi, G., Islam, K., and Sambuy, Y. (1994). D-cycloserine uses an active transport mechanism in the human intestinal cell line Caco 2. Antimicrob. Agents Chemother. 38, 1239-1245. doi: 10.1128/aac.38.6.1239

Rapali, P., Radnai, L., Süveges, D., Harmat, V., Tölgyesi, F., Wahlgren, W. Y., et al. (2011). Directed evolution reveals the binding motif preference of the LC8/DYNLL hub protein and predicts large numbers of novel binders in the human proteome. PLoS One 6:e18818. doi: 10.1371/journal.pone.0018818

Rey, G., Cesbron, F., Rougemont, J., Reinke, H., Brunner, M., and Naef, F. (2011). Genome-wide and phase-specific DNA-binding rhythms of BMAL1 control circadian output functions in mouse liver. PLoS Biol. 9:e1000595. doi: 10.1371/ journal.pbio.1000595

Ronshaugen, M., McGinnis, N., and McGinnis, W. (2002). Hox protein mutation and macroevolution of the insect body plan. Nature 415, 914-917. doi: 10.1038/ nature716

Schwede, M., Garbett, K., Mirnics, K., Geschwind, D. H., and Morrow, E. M. (2014). Genes for endosomal NHE6 and NHE9 are misregulated in autism brains. Mol. Psychiatry 19, 277-279. doi: 10.1038/mp.2013.28

Sebesta, M., Cooper, C. D. O., Ariza, A., Carnie, C. J., and Ahel, D. (2017). Structural insights into the function of ZRANB3 in replication stress response. Nat. Commun. 8:15847. doi: 10.1038/ncomms15847

Sharma, A., Dehzangi, A., Lyons, J., Imoto, S., Miyano, S., Nakai, K., et al. (2014). Evaluation of sequence features from intrinsically disordered regions for the estimation of protein function. PLoS One 9:e89890. doi: 10.1371/journal.pone. 0089890

Sharma, R., Bayarjargal, M., Tsunoda, T., Patil, A., and Sharma, A. (2018). MoRFPred-plus: computational identification of MoRFs in protein sequences using physicochemical properties and HMM profiles. J. Theor. Biol. 437, 9-16. doi: 10.1016/j.jtbi.2017.10.015
Slee, J. A., and Levine, T. P. (2019). Systematic prediction of FFAT motifs across eukaryote proteomes identifies nucleolar and eisosome proteins with the predicted capacity to form bridges to the endoplasmic reticulum. Contact 2, 1-21. doi: $10.1177 / 2515256419883136$

Sørensen, C. S., and Kjaergaard, M. (2019). Effective concentrations enforced by intrinsically disordered linkers are governed by polymer physics. Proc. Natl. Acad. Sci. U.S.A. 116, 23124-23131. doi: 10.1073/pnas.19048 13116

Sotomayor Pérez, A.-C., Karst, J. C., Davi, M., Guijarro, J. I., Ladant, D., and Chenal, A. (2010). Characterization of the regions involved in the calciuminduced folding of the intrinsically disordered RTX motifs from the bordetella pertussis adenylate cyclase toxin. J. Mol. Biol. 397, 534-549. doi: 10.1016/j.jmb. 2010.01.031

Staby, L., O'Shea, C., Willemoës, M., Theisen, F., Kragelund, B. B., and Skriver, K. (2017). Eukaryotic transcription factors: paradigms of protein intrinsic disorder. Biochem. J. 474, 2509-2532. doi: 10.1042/BCJ20160631

Staller, M. V., Holehouse, A. S., Swain-Lenz, D., Das, R. K., Pappu, R. V., and Cohen, B. A. (2018). A high-throughput mutational scan of an intrinsically disordered acidic transcriptional activation domain. Cell Syst. 6, 444-455.e6. doi: 10.1016/j.cels.2018.01.015

Stein, A., and Aloy, P. (2008). Contextual specificity in peptide-mediate protein interactions. PLoS One 3:e2524. doi: 10.1371/journal.pone.0002524

Stender, E. G., O'Shea, C., and Skriver, K. (2015). Subgroup-specific intrinsic disorder profiles of Arabidopsis NAC transcription factors: identification of functional hotspots. Plant Signal. Behav. 10:e1010967. doi: 10.1080/15592324. 2015.1010967

Teyra, J., Sidhu, S. S., and Kim, P. M. (2012). Elucidation of the binding preferences of peptide recognition modules: SH3 and PDZ domains. FEBS Lett. 586, 2631-2637. doi: 10.1016/j.febslet.2012.05.043

Tompa, P., Davey, N. E., Gibson, T. J., and Babu, M. M. (2014). A million peptide motifs for the molecular biologist. Mol. Cell 55, 161-169. doi: 10.1016/j.molcel. 2014.05.032

Toto, A., Camilloni, C., Giri, R., Brunori, M., Vendruscolo, M., and Gianni, S. (2016). Molecular recognition by templated folding of an intrinsically disordered protein. Sci. Rep. 6:21994. doi: 10.1038/srep 21994

Uversky, V. N. (2018). Intrinsic disorder, protein-protein interactions, and disease. Adv. Protein Chem. Struct. Biol. 110, 85-121. doi: 10.1016/bs.apcsb.2017.06.005

Uversky, V. N., Gillespie, J. R., Millett, I. S., Khodyakova, A. V., Vasiliev, A. M., Chernovskaya, T. V., et al. (1999). Natively unfolded human prothymosin alpha adopts partially folded collapsed conformation at acidic pH. Biochemistry 38, 15009-15016. doi: 10.1021/bi990752\%2B

Uyar, B., Weatheritt, R. J., Dinkel, H., Davey, N. E., and Gibson, T. J. (2014). Proteome-wide analysis of human disease mutations in short linear motifs: neglected players in cancer? Mol. Biosyst. 10, 2626-2642. doi: 10.1039/ c4mb00290c

Vancraenenbroeck, R., Harel, Y. S., Zheng, W., and Hofmann, H. (2019). Polymer effects modulate binding affinities in disordered proteins. Proc. Natl. Acad. Sci. U.S.A. 116, 19506-19512. doi: 10.1073/pnas.1904997116

Wang, J., Choi, J.-M., Holehouse, A. S., Lee, H. O., Zhang, X., Jahnel, M., et al. (2018). A molecular grammar governing the driving forces for phase separation of prion-like RNA binding proteins. Cell 174, 688-699.e16. doi: 10.1016/j.cell. 2018.06.006

Warfield, L., Tuttle, L. M., Pacheco, D., Klevit, R. E., and Hahn, S. (2014). A sequence-specific transcription activator motif and powerful synthetic variants that bind Mediator using a fuzzy protein interface. Proc. Natl. Acad. Sci. U.S.A. 111, E3506-E3513. doi: 10.1073/pnas.1412088111

Wicky, B. I. M., Shammas, S. L., and Clarke, J. (2017). Affinity of IDPs to their targets is modulated by ion-specific changes in kinetics and residual structure. Proc. Natl. Acad. Sci. U.S.A. 114, 9882-9887. doi: 10.1073/pnas.170510 5114

Xiang, W., Menges, S., Schlachetzki, J. C., Meixner, H., Hoffmann, A.-C., Schlötzer-Schrehardt, U., et al. (2015). Posttranslational modification and mutation of histidine 50 trigger alpha synuclein aggregation and toxicity. Mol. Neurodegener. 10:8. doi: 10.1186/s13024-015-0004-0

Yi, S., Boys, B. L., Brickenden, A., Konermann, L., and Choy, W.-Y. (2007). Effects of zinc binding on the structure and dynamics of the intrinsically disordered 
protein prothymosin alpha: evidence for metalation as an entropic switch. Biochemistry 46, 13120-13130. doi: 10.1021/bi7014822

Zarrinpar, A., Park, S. H., and Lim, W. A. (2003). Optimization of specificity in a cellular protein interaction network by negative selection. Nature 426, 676-680. doi: 10.1038 /nature02178

Zaslavsky, B. Y., Ferreira, L. A., Darling, A. L., and Uversky, V. N. (2018). The solvent side of proteinaceous membrane-less organelles in light of aqueous twophase systems. Int. J. Biol. Macromol. 117, 1224-1251. doi: 10.1016/j.ijbiomac. 2018.06.030

Zhao, H., Carney, K. E., Falgoust, L., Pan, J. W., Sun, D., and Zhang, Z. (2016). Emerging roles of $\mathrm{Na}+/ \mathrm{H}+$ exchangers in epilepsy and developmental brain disorders. Prog. Neurobiol. 138-140, 19-35. doi: 10.1016/j.pneurobio.2016.02. 002

Zheleva, D. I., Zhelev, N. Z., Fischer, P. M., Duff, S. V., Warbrick, E., Blake, D. G., et al. (2000). A quantitative study of the in vitro binding of the C-terminal domain of p21 to PCNA: affinity, stoichiometry, and thermodynamics. Biochemistry 39, 7388-7397. doi: 10.1021/bi99 $2498 \mathrm{r}$

Conflict of Interest: The authors declare that the research was conducted in the absence of any commercial or financial relationships that could be construed as a potential conflict of interest.

Copyright $\odot 2020$ Bugge, Brakti, Fernandes, Dreier, Lundsgaard, Olsen, Skriver and Kragelund. This is an open-access article distributed under the terms of the Creative Commons Attribution License (CC BY). The use, distribution or reproduction in other forums is permitted, provided the original author(s) and the copyright owner(s) are credited and that the original publication in this journal is cited, in accordance with accepted academic practice. No use, distribution or reproduction is permitted which does not comply with these terms. 